\title{
Effects of recent population bottlenecks on reconstructing the demographic history of prairie-chickens
}

\author{
JEFF A. JOHNSON,${ }^{*}+$ PETER O. DUNN ${ }^{*}$ and JUAN L. BOUZAT \\ *Department of Biological Sciences, University of Wisconsin-Milwaukee, PO Box 413, Milwaukee, WI 53201, USA, +Department of \\ Ecology E Evolutionary Biology, University of Michigan Museum of Zoology, 1109 Geddes Avenue, Ann Arbor, MI 48109, USA and \\ The Peregrine Fund, 5668 West Flying Hawk Lane, Boise, ID 83709, USA, †Department of Biological Sciences, Bowling Green State \\ University, Life Sciences Building, Bowling Green, OH 43403, USA
}

\begin{abstract}
Current methods of DNA sequence analysis attempt to reconstruct historical patterns of population structure and growth from contemporary samples. However, these techniques may be influenced by recent population bottlenecks, which have the potential to eliminate lineages that reveal past changes in demography. One way to examine the performance of these demographic methods is to compare samples from populations before and after recent bottlenecks. We compared estimates of demographic history from populations of greater prairie-chickens (Tympanuchus cupido) before and after recent bottlenecks using four common methods (nested clade analysis [NCA], Tajima's D, mismatch distribution, and MDIV). We found that NCA did not perform well in the presence of bottleneck events, although it did recover some genetic signals associated with increased isolation and the extinction of intermediate populations. The majority of estimates for Tajima's $D$, including those from bottlenecked populations, were not significantly different from zero, suggesting our data conformed to neutral expectations. In contrast, mismatch distributions including the raggedness index were more likely to identify recently bottlenecked populations with this data set. Estimates of population mutation rate $(\theta)$, population divergence time $(t)$, and time to the most recent common ancestor (TMRCA) from MDIV were similar before and after bottlenecks; however, estimates of gene flow $(M)$ were significantly lower in a few cases following a bottleneck. These results suggest that caution should be used when assessing demographic history from contemporary data sets, as recently fragmented and bottlenecked populations may have lost lineages that affect inferences of their demographic history.
\end{abstract}

Keywords: bottleneck, coalescent, incomplete lineage sorting, MDIV, mismatch distribution, nested clade analysis, Tympanuchus

Received 26 September 2006; revision accepted 8 January 2007

\section{Introduction}

Studies of genetic variation within and among populations provide insights into their evolutionary history (Avise 2004; Singh \& Uyenoyama 2004) as well as important information for conserving biodiversity (DeSalle \& Amato 2004; Hedrick 2004a, b). Over the last decade, there have been major advances in assessing population genetic structure using a number of different molecular techniques (Smith \& Wayne 1996; Emerson et al. 2001; Pearse \& Crandall 2004; Manel

Correspondence: Jeff A. Johnson, Fax: 734763 4080; E-mail: jeffaj@umich.edu et al. 2005). Many of these studies use current patterns of genetic variation to infer historical events such as population expansions from refugia or the occurrence of past population bottlenecks. This information is valuable for studies of evolution and conservation because it allows inferences about the processes that led to current levels of genetic variation; however, studies based on data from contemporary populations alone may provide misleading information (e.g. Leonard et al. 2000; Miller \& Waits 2003; Hofreiter et al. 2004; Johnson \& Dunn 2006). Unfortunately, few studies have historical samples available for testing whether current patterns are the result of recent (e.g. past several hundred years) or more ancient processes. Therefore, an empirical 
evaluation of the performance and limitations of commonly used methods to infer demographic history is of particular interest.

Demographic history can consist of a complex variety of processes at different temporal scales. For example, processes such as isolation by distance, divergence (in isolation or with gene flow), and population expansions typically occur over long timescales (thousands of generations), while population contractions (i.e. bottlenecks) and dispersal events typically occur over shorter timescales (tens or hundreds of generations). Coalescent theory has helped our understanding of how demographic processes influence levels and patterns of DNA sequence variation (see Hein et al. 2005) because it allows a more rigorous assessment of the stochastic process of lineage sorting by separating out genealogical processes from neutral mutational processes, which are typically represented by $\theta$ (or $4 N_{\mathrm{e}} \mu$, where $N_{\mathrm{e}}$ is the effective number of diploid individuals and $\mu$ is the mutation rate).

Empirical studies rarely recognize the potential effects that recent population bottlenecks may have on both genealogies and the interpretation of demographic history, yet bottlenecks are likely to be common among contemporary populations, particularly as a result of recent human activities. The severity and longevity of a population bottleneck will influence levels of neutral variability; however, due to the randomness of genetic drift and high stochastic variance, the result of a bottleneck from the genealogical viewpoint is largely unpredictable (Wakeley 2004). For example, a contraction in population size lasting longer than $2 N_{\mathrm{e}}$ generations can remove most if not all genetic variability from a population, though some loci may retain considerable variation depending on $N_{\mathrm{e}}$ prior to the bottleneck (see Fig. 4 in Harpending et al. 1998). How this affects the overall interpretation of demographic history will depend on the particular methods used in the study (Gaggiotti \& Excoffier 2000; Arbogast et al. 2002; Hey \& Machado 2003; Knowles 2004).

In this study, we examined the performance of nested clade analysis (NCA; Templeton et al. 1995), Tajima's D (Tajima 1989b), mismatch distribution (Rogers \& Harpending 1992), and MDIV (Nielsen \& Wakeley 2001), all commonly used methods for reconstructing the demographic history of populations at both long- and short-term temporal scales. In particular, we were interested in determining whether recent population bottlenecks influenced the results of each method. Using a data set of greater prairie-chicken (Tympanuchus cupido) mitochondrial DNA (mtDNA) sequences from two temporal samples (a historical sample, 1854-1954; and a contemporary sample, primarily 1990 2001; Table 1), we were able to compare demographic inferences from each of the methods studied. The primary difference between the two temporal data sets consists of various degrees of increased fragmentation followed by isolation; in several cases populations have also undergone severe population contractions (bottlenecks). How these processes affect the final demographic inferences for each temporal data set are of particular interest given that the two data sets are only 50-100 years apart.

The greater prairie-chicken consists of three T. cupido subspecies: the greater prairie-chicken (T.c. pinnatus), the critically endangered Attwater's prairie-chicken (T.c. attwateri) and the heath hen (T.c.cupido), which went extinct in 1932. This genus also includes the lesser prairie-chicken (Tympanuchus pallidicinctus) and sharp-tailed grouse (Tympanuchus phasianellus). Although these species and subspecies are easily distinguishable based on morphological characters ( Johnsgard 2002), molecular methods using traditional phylogenetic approaches suggest that the history shaping this genus is fairly recent as the majority of currently recognized Tympanuchus species appear polyphyletic due to incomplete lineage sorting and ancestral polymorphisms (Dimcheff et al. 2002; Drovetski 2002; Johnson \& Dunn 2006; Spaulding et al. 2006). This close relationship among Tympanuchus taxa is consistent with an expansion into their current geographical distributions as glaciers retreated in North America about 10000 вP (Pielou 1991; Dawson 1992; Johnsgard 2002).

Historical abundance records and genetic evidence suggest that populations of greater prairie-chickens were largely connected forming a panmictic population in large blocks of open grassland throughout midwestern North America (Schroeder \& Robb 1993; Johnsgard 2002; Johnson et al. 2003; Ross et al. 2006). Similarly, Attwater's prairiechicken occupied a large contiguous area in central Texas and along the coast into Louisiana (Johnsgard 2002; Silvy et al. 2004). Within the last 50-150 years, however, populations of prairie-chickens have become highly fragmented and reduced in size, and in some cases extirpated (Fig. 1). A number of populations, particularly those in Wisconsin and Illinois, possess significantly lower levels of genetic diversity than larger populations in Kansas, Nebraska, South Dakota, and Minnesota, including historical samples collected from the same geographical area prior to their decline (Bouzat et al. 1998a, 1998b; Johnson et al. 2003, 2004; this study). This reduction in genetic diversity has coincided with increased habitat fragmentation, isolation, and population contractions (i.e. bottlenecks; see Bouzat et al. 1998b; Johnson et al. 2004; Johnson \& Dunn 2006).

The availability of samples of prairie-chickens from populations before and after documented population bottlenecks provide a rare opportunity to evaluate the performance of genetic methods commonly used to infer demographic histories. To date, most inferences of historical processes within Tympanuchus have been based on either a phylogenetic or phylogeographical approach using single gene trees. However, we might expect methods based on coalescent theory to provide more robust estimates of the 
Table 1 Mitochondrial control region DNA sequence variation and Tajima's D estimates from historical and contemporary populations of prairie-chickens. Blanks indicate sample sizes were too small to make estimates

\begin{tabular}{|c|c|c|c|c|c|}
\hline Sample period and population & $N$ & $\begin{array}{l}\text { No. of } \\
\text { haplotypes }\end{array}$ & $\begin{array}{l}\text { Haplotype diversity } \\
(h \pm S E)\end{array}$ & $\begin{array}{l}\text { Nucleotide diversity } \\
(\pi \pm \text { SE })\end{array}$ & Tajima's $D$ \\
\hline \multicolumn{6}{|l|}{ Historical populations (1854-1954) } \\
\hline Greater prairie-chicken (all pops) & 216 & 71 & $0.928 \pm 0.001$ & $0.010 \pm 0.000$ & -1.522 \\
\hline Alberta & 2 & 2 & $1.000 \pm 0.000$ & $0.008 \pm 0.003$ & \\
\hline Manitoba & 5 & 4 & $0.900 \pm 0.072$ & $0.007 \pm 0.003$ & -0.668 \\
\hline North Dakota-north & 13 & 10 & $0.949 \pm 0.014$ & $0.013 \pm 0.001$ & -0.871 \\
\hline Minnesota-northwest & 5 & 4 & $0.900 \pm 0.072$ & $0.008 \pm 0.001$ & -0.747 \\
\hline Minnesota-central & 14 & 10 & $0.945 \pm 0.012$ & $0.016 \pm 0.001$ & -0.662 \\
\hline Iowa & 8 & 6 & $0.929 \pm 0.030$ & $0.010 \pm 0.001$ & 1.433 \\
\hline South Dakota & 7 & 5 & $0.905 \pm 0.039$ & $0.011 \pm 0001$ & 0.393 \\
\hline Nebraska-central & 14 & 14 & $1.000 \pm 0.000$ & $0.014 \pm 0.000$ & -1.027 \\
\hline Kansas/Nebraska-southeast & 7 & 4 & $0.810 \pm 0.049$ & $0.009 \pm 0.001$ & 0.416 \\
\hline Missouri-east & 5 & 3 & $0.700 \pm 0.097$ & $0.005 \pm 0.001$ & 0.273 \\
\hline Missouri-southwest & 2 & 2 & $1.000 \pm 0.000$ & $0.005 \pm 0.001$ & \\
\hline Oklahoma & 1 & 1 & & & \\
\hline Michigan-Upper Peninsula & 12 & 7 & $0.879 \pm 0.022$ & $0.009 \pm 0.001$ & -0.389 \\
\hline Michigan-central & 8 & 2 & $0.250 \pm 0.064$ & $0.004 \pm 0.001$ & -1.640 \\
\hline Michigan-southeast & 12 & 6 & $0.758 \pm 0.035$ & $0.005 \pm 0.000$ & 0.200 \\
\hline Illinois-north & 10 & 4 & $0.711 \pm 0.037$ & $0.004 \pm 0.000$ & -1.276 \\
\hline Illinois-south & 14 & 5 & $0.824 \pm 0.015$ & $0.004 \pm 0.000$ & 0.562 \\
\hline Wisconsin-south central & 4 & 4 & $1.000 \pm 0.000$ & $0.009 \pm 0.001$ & 0.674 \\
\hline Wisconsin-Mead $†$ & 18 & 11 & $0.941 \pm 0.008$ & $0.010 \pm 0.001$ & -0.669 \\
\hline Wisconsin-Paul Olsont & 19 & 10 & $0.860 \pm 0.016$ & $0.008 \pm 0.000$ & -0.041 \\
\hline Wisconsin-Buena Vista $\ddagger$ & 19 & 10 & $0.889 \pm 0.013$ & $0.012 \pm 0.001$ & -0.427 \\
\hline Wisconsin-Leolat & 17 & 9 & $0.890 \pm 0.013$ & $0.012 \pm 0.000$ & -0.046 \\
\hline Attwater's prairie-chicken§ & 19 & 11 & $0.912 \pm 0.011$ & $0.009 \pm 0.000$ & -0.162 \\
\hline Refugio County & 6 & 4 & $0.867 \pm 0.053$ & $0.008 \pm 0.001$ & -0.251 \\
\hline Colorado County & 10 & 8 & $0.933 \pm 0.024$ & $0.010 \pm 0.000$ & -0.076 \\
\hline Jefferson County & 3 & 3 & $1.000 \pm 0.000$ & $0.005 \pm 0.001$ & \\
\hline \multicolumn{6}{|c|}{ Contemporary populations (1974-2001) } \\
\hline Greater prairie-chicken (all pops) & 282 & 64 & $0.925 \pm 0.000$ & $0.013 \pm 0.003$ & -1.014 \\
\hline Minnesota-northwest $\mathbb{I}$ & 20 & 9 & $0.847 \pm 0.014$ & $0.009 \pm 0.000$ & -1.387 \\
\hline Minnesota-west central§ & 20 & 8 & $0.889 \pm 0.008$ & $0.010 \pm 0.000$ & -0.456 \\
\hline South Dakota-central & 20 & 14 & $0.958 \pm 0.006$ & $0.012 \pm 0.000$ & -0.706 \\
\hline Nebraska-north & 20 & 15 & $0.968 \pm 0.006$ & $0.012 \pm 0.000$ & -0.915 \\
\hline Nebraska-centralII & 20 & 15 & $0.968 \pm 0.006$ & $0.009 \pm 0.001$ & -1.049 \\
\hline Nebraska-southeast & 20 & 12 & $0.900 \pm 0.012$ & $0.001 \pm 0.000$ & -0.374 \\
\hline Kansas-east centralII & 20 & 11 & $0.858 \pm 0.015$ & $0.010 \pm 0.002$ & -0.941 \\
\hline Missouri-southwest $\mathbb{I}$ & 20 & 8 & $0.842 \pm 0.010$ & $0.012 \pm 0.000$ & -0.218 \\
\hline Oklahoma-northwest & 10 & 6 & $0.889 \pm 0.024$ & $0.012 \pm 0.001$ & 0.159 \\
\hline Illinois-south & 32 & 4 & $0.728 \pm 0.007$ & $0.005 \pm 0.000$ & 0.526 \\
\hline Wisconsin-Mead+II & 20 & 3 & $0.484 \pm 0.025$ & $0.010 \pm 0.002$ & 1.283 \\
\hline Wisconsin-Paul Olson+II & 20 & 4 & $0.679 \pm 0.017$ & $0.016 \pm 0.004$ & $2.744^{*}$ \\
\hline Wisconsin-Buena Vista†II & 20 & 5 & $0.511 \pm 0.029$ & $0.013 \pm 0.003$ & 0.738 \\
\hline Wisconsin-LeolatII & 20 & 6 & $0.784 \pm 0.014$ & $0.014 \pm 0.003$ & 1.697 \\
\hline Attwater's prairie-chicken§ & 36 & 8 & $0.751 \pm 0.011$ & $0.008 \pm 0.001$ & -0.042 \\
\hline Refugio County & 10 & 2 & $0.467 \pm 0.042$ & $0.007 \pm 0.001$ & 1.325 \\
\hline Colorado County & 13 & 5 & $0.833 \pm 0.017$ & $0.007 \pm 0.002$ & 0.993 \\
\hline Galveston County & 13 & 4 & $0.679 \pm 0.025$ & $0.007 \pm 0.001$ & -0.689 \\
\hline
\end{tabular}

*Tajima's $D$ statistic, $P<0.01$ (significance indicates the violation of neutral expectations).

†Johnson et al. (2004), †Bellinger et al. (2003), §Johnson \& Dunn (2006), IJohnson et al. (2003). 


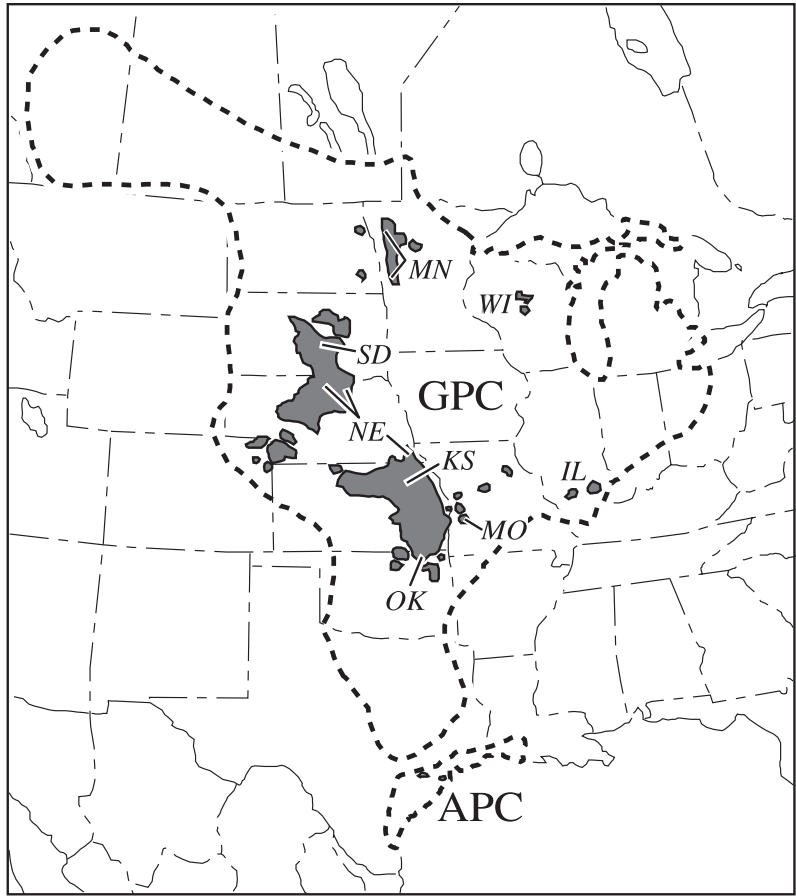

Fig. 1 Map of North America showing historical (dotted line) and contemporary distributions for greater (GPC) and Attwater's (APC) prairie-chickens. Sample locations are indicated for contemporary GPC, labelled with the state (i.e. Illinois, IL; Kansas, KS; Missouri, MO; Minnesota, MN; Nebraska, NE; Oklahoma, OK; South Dakota, $\mathrm{SD}$; and Wisconsin, WI).

demographic history of prairie-chickens, particularly because these methods account for retained ancestral polymorphisms and, thus, help control for incomplete lineage sorting. In this study, we were particularly interested in the ability of recent phylogenetic and coalescent methods to infer demographic history when samples were taken before and after well-documented recent episodes of fragmentation and population bottlenecks.

\section{Materials and methods}

\section{Sampling and DNA extractions}

DNA was extracted from blood and feather tissue of adult greater prairie-chickens $(n=282$; Table 1$)$ collected from contemporary populations in Missouri (Barton and Dade Counties), Kansas (Wabaunsee County), Nebraska (Cherry, Garfield, and Johnson Counties), Minnesota (Norman and Wilken Counties), South Dakota (Fort Pierre National Grasslands), Oklahoma (Osage County), Illinois (Jasper County) and Wisconsin (Mead, Paul Olson, Buena Vista, and Leola management areas occupying four adjacent counties; see Johnson et al. 2003) using methods described previously (Bouzat et al. 1998a; Johnson et al. 2003). All contemporary populations were sampled between the years
1997 and 2001, with the exception of Illinois, which was sampled between 1974 and 1993 prior to a series of translocation events from other states (see Bouzat et al. 1998a; Westemeier et al. 1998). Contemporary Attwater's prairiechicken samples ( $n=36$; Table 1 ) were collected from Texas populations in Refugio, Colorado, and Galveston Counties between the years 1990 and 1994. Greater prairie-chicken populations from Wisconsin and Illinois and Attwater's prairie-chicken populations from Texas are all populations that have experienced recent bottleneck events, which we used to define contemporary (post-bottleneck) and historical (prebottleneck) populations.

For the analysis of historical populations (1854-1954; Table 1), DNA was extracted from either toe pads or feathers of museum specimens (Attwater's prairie-chicken, $n=19$, and greater prairie-chicken, $n=143$; see Bouzat et al. 1998b; Johnson \& Dunn 2006; Ross et al. 2006; Table S1, Supplementary material) or from wings collected during the last greater prairie-chicken hunting seasons (1951-54) in Wisconsin ( $n=73$; see Bellinger et al. 2003; Johnson et al. 2004). To reduce the potential for contamination with contemporary prairie-chicken samples, extractions from historical samples were conducted in an independent laboratory facility that had not been exposed previously to prairie-chicken DNA, and all Attwater's prairie-chicken samples were extracted and amplified separate from other taxonomic groups. Filtered pipette tips were used exclusively, and extractions in subsets of no more than 16 individuals were conducted at any given time. Blank extraction controls were included with each subset, and all controls were negative when subjected to polymerase chain reaction (PCR).

\section{Mitochondrial DNA sequencing}

Two primer pairs, 521H (Quinn \& Wilson 1993)/186 L (Johnson \& Dunn 2006) and 272H (Johnson \& Dunn 2006) / $16775 \mathrm{~L}$ (Quinn 1992) were used to sequence 394 basepairs (bp) from the $5^{\prime}$ end of the mitochondrial DNA control region. PCR was conducted following methods in Johnson et al. (2003, 2004) and Johnson \& Dunn (2006) with no indication of amplification of any copies of nuclear origin, or numts (see Johnson et al. 2003). Samples were run on $2 \%$ low melting point agarose gels and identified bands were extracted using DNAquick QIAGEN kits (QIAGEN). Following gel extraction, sequences were either obtained using Beckman Coultier TDCS kit and run on a CEQ 8000 capillary sequencer or with ABI Big Dye Terminator chemistry run on an ABI 3730 automated sequencer.

\section{Statistical analyses}

Estimates of genetic diversity. Levels of mtDNA diversity were investigated by comparing population estimates of mitochondrial haplotype diversity $(h)$ and nucleotide 
diversity $(\pi)$, and both measures were calculated using the program DNASP version 4.10.4 (Rozas et al. 2003). Standard errors (S.E.) were estimated for both haplotype and nucleotide diversity measures for each population. In addition, we estimated the total number of mitochondrial haplotypes as well as the number of unique and shared haplotypes among population and temporal samples.

Nested clade analysis. Analyses based on networks are thought to be more accurate at representing historical processes at the intraspecific level because they take into account population level processes (Excoffier \& Smouse 1994; Posada \& Crandall 2001). One such network-type procedure, statistical parsimony or TCS, has been used extensively to infer population level genealogies when divergences are low (see Templeton 2004). By combining statistical parsimony with geographical information in the form of a nested clade analysis (NCA), one can identify different historical processes that have influenced the geographical distribution of genetic variation within a haplotype network (Templeton et al. 1995). This ability to identify historical processes is based on the prediction from coalescent theory that older haplotypes should have wider geographical distributions and clades at the tips of the network will be younger than the interior clades to which they are connected (Castelloe \& Templeton 1994). It is important to note that this prediction assumes a panmictic population. In principle, these patterns should allow one to infer the temporal sequence of events within series of nested clades.

An unrooted network of mtDNA haplotypes was constructed using the program Tcs version 1.21 (Clement et al. 2000) with $95 \%$ parsimoniously plausible branch connections between haplotypes. To conduct NCA, haplotypes in each resulting network were nested using methods described in Templeton et al. (1987), Templeton \& Sing (1993), Crandall (1996), and Templeton (1998). Network and nesting ambiguities were resolved following methods described in Crandall \& Templeton (1993) and Templeton \& Sing (1993). Tip-interior designations were assigned to each clade-group, and geographical information was then included within each of the nested sets of haplotypes or clades. Using the program GEODIs version 2.4 (Posada et al. 2000), significance $(\alpha=0.05)$ of clade-group distance measures $\left(D_{\mathrm{c}^{\prime}} D_{\mathrm{n}^{\prime}}\right.$ and I-T) were determined by comparisons with a null distribution from 10000 permutation replicates, which assumed no geographical associations among haplotypes (Templeton 1998). Demographic inferences were then made following the most recent published key at: http://darwin.uvigo.es (downloaded November 2005).

We conducted separate NCA on the historical and contemporary data sets to determine if inferences of longterm demographic processes (e.g. isolation by distance and allopatry) and recent demographic events (such as increased isolation, population extinctions, and recent demographic bottlenecks) were similar using the two data sets. We also conducted NCA using a combined data set that included the historical and contemporary samples, but excluded samples from the contemporary bottlenecked populations. This allowed us to determine if differences in results between analyses of the two temporal data sets were due to differences in sample size. This approach assumes minimal changes in haplotype frequencies between the historical and contemporary non- and prebottleneck populations. This assumption is supported by earlier studies using both microsatellite and mtDNA data (see Johnson et al. 2003, 2004; Johnson \& Dunn 2006).

Tajima's D and neutral expectations. The program DNASP version 4.10.4 (Rozas et al. 2003) was used to calculate Tajima's $D$ to determine whether control region sequences in our population samples conformed to neutral expectations (Tajima 1989a). This statistic is based on the relationship between the average number of pairwise differences $(\hat{\pi})$ and the number of segregating sites $(S)$ in a DNA sequence that is predicted by the basic coalescent model, or the standard null model of sequence evolution following equilibrium neutral expectations. It assumes that $\hat{\pi}$ and $S$ are unbiased estimates of $\theta$, which is proportional to the product of $N_{\mathrm{e}}$ and the mutation rate $(\mu)$. Departures from the null model can be caused by many factors, such as changes in population size (e.g. expanding) or linkage to a locus under directional selection, both of which can lead to an excess of low frequency variants and negative $D$ values. In contrast, processes such as population subdivision, balancing selection or recent population bottlenecks can cause an excess of intermediate frequency variants leading to positive $D$ values (Tajima 1989b, 1993; Simonsen et al. 1995; Fay \& Wu 1999; Nielsen 2001; Hein et al. 2005).

Mismatch distribution. To test for historical population expansion events within prairie-chicken populations, we compared the observed frequency distribution of pairwise nucleotide differences among individuals (i.e. mismatch distribution; Rogers \& Harpending 1992) with expected distributions from a population expansion using the program ARLEQUIN version 3.0 (Excoffier et al. 2005). Populations at demographic equilibrium or in decline should provide a multimodal distribution of pairwise differences, whereas populations that have experienced a sudden demographic expansion should display a star-shaped phylogeny and a unimodal distribution (Slatkin \& Hudson 1991; Rogers \& Harpending 1992). However, recent changes in population size may not be detectable in mismatch distribution analyses due to threshold effects, time lags, or earlier demographic events that may mask the effects of recent events (Rogers \& Harpending 1992; Lavery et al. 1996).

The method assumes an instantaneous stepwise expansion model from a population of $N_{0}$ to $N_{1}$ individuals, $t$ 
generations ago, followed by demographic equilibrium. Three parameters were estimated: $\theta_{0}=2 N_{0} \mu, \theta_{1}=2 N_{1} \mu$, and $\tau=2 \mu t$, where $\mu$ is the mutation rate for the locus. Five hundred parametric bootstrap replicates were used to generate an expected distribution using a model of sudden demographic expansion (Excoffier et al. 2005). P values were then calculated as the proportion of simulations producing a larger sumof-squared deviation (SSD) than the observed SSD. The raggedness index of the observed mismatch distribution was also calculated for each of the populations and its significance determined similar to SSD as implemented in ARLEQUIN. This measure attempts to quantify the smoothness of the observed mismatch distribution. Small raggedness values are typical of an expanding population whereas higher values are observed among stationary or bottlenecked populations (Harpending et al. 1993; Harpending 1994).

Both contemporary and historical data sets with geographical regions, or populations, consisting of at least eight individuals were used to estimate parameters of mismatch distributions. Geographically proximate historical populations were combined to increase sample sizes when necessary. If the sudden expansion model was not rejected, then $\tau$ was converted to time since expansion $(t)$ in years before present [увг $(t=\tau / 2 \mu)$ ]. Using mtDNA control region data and fossil calibrations from Drovetski (2003), we estimated $\mu$ using sequence data corresponding to the alignment used in this study, including indels (for $395 \mathrm{bp}, \mu=5.6 \times 10^{-5}$ substitutions per locus per year, or $4.6 \times 10^{-5}-7.3 \times 10^{-5}$ given uncertainty in the fossil calibration), and assuming a 1-year generation time for female prairie-chickens. To account for uncertainty in fossil calibration, values for $t$ were rounded to the nearest $10^{3}$. Similar to the original sequence length (1206 bp) used in Drovetski (2003), the program MODELTEST version 3.6 (Posada \& Crandall 1998) was used to select the TVM $+\mathrm{I}+\mathrm{G}$ as the appropriate model for the control region sequences used for this calibration.

MDIV Analyses. We used the program MDIV to determine whether two populations possessed shared polymorphisms due to recent gene flow or incomplete lineage sorting following gene coalescence (see Nielsen \& Wakeley 2001; Hey \& Nielsen 2004). Using the basic isolation with migration model, the program jointly estimates theta, or the effective population size scaled by the neutral mutation rate $(\theta=$ $2 N_{\text {ef }} \mu$, where $N_{\text {ef }}$ is the effective female population size and $\mu$ is the mutation rate per locus per year), symmetric gene flow $\left(M=N_{\text {ef }} m\right.$, where $m$ is the fraction of effective migrants per generation), divergence time $\left(T=t_{1} / N_{\mathrm{ef}}\right.$, where $t_{1}$ is the population divergence time in years before present), and time to the most recent common ancestor (TMRCA $=t_{2} /$ $N_{\text {ef }}$, where $t_{2}$ is the gene coalescence time in years before present). The parameters estimating population divergence time and TMRCA are then used to determine the degree of isolation between populations. One must note that this method assumes that the populations (or species) being analysed are each other's closest relatives, that each population is panmictic, and that population sizes do not change over time (Nielsen \& Wakeley 2001; Hey \& Nielsen 2004; Hey 2005). This last assumption was obviously violated with our bottlenecked populations; however, we were primarily interested in the effect of recent bottlenecks on these parameter estimates, as many researchers may not know if their study populations have experienced population bottlenecks.

The recently developed program IM (Hey \& Nielsen 2004; Hey 2005) also uses the basic isolation with migration model, and it allows for population size changes by adding another parameter ( $s$, splitting factor) to those given above. However, we were unable to use Im with our data set while including this parameter ( $s$ ) because estimates failed to converge even after the program had run for over 15 million generations with metropolis-coupling invoked (> 5 chains; see IM documentation). Given that the main difference between MDIV and IM pertains to the latter's ability to include multiple independent loci, each with specific mutation scalars (see Hey \& Nielsen 2004), this approach while using the parameter $s$ may be more appropriate with additional loci, and therefore beyond the scope of this study (see Knowles 2004). Our use of MDIV for comparative purposes between bottlenecked populations, while using a singlelocus data set for a large number of pairwise comparisons $(N>400)$, is therefore justified.

Divergence time, TMRCA and other demographic parameters were estimated between pairs of populations using MDIV. For comparative purposes, we estimated parameters between nonbottlenecked contemporary populations grouped as a single population (GPC nonbottlenecked) and populations sampled either before or after recent bottleneck events (Wisconsin, Illinois and Attwater's prairiechicken populations). This approach assumes that haplotype frequencies in nonbottlenecked populations have not changed significantly over the sampled time periods and still reflect historical associations ( $\sim 100$ years) of overall connectivity throughout their distribution (see also Johnson et al. 2003, 2004; Johnson \& Dunn 2006). In some cases (e.g. in Wisconsin), these temporal data sets represent pre- and post-bottleneck samples separated by as little as 50 years. If MDIV provides estimates of population divergence time and TMRCA that are robust to recent population bottlenecks, then we would expect the estimates to be similar regardless of when the Wisconsin, Illinois and Attwater's prairie-chicken populations were sampled (i.e. before or after the bottleneck). In contrast, estimates of $M$ should decrease following a bottleneck event (by definition); however, estimates of $M$ between more divergent populations or taxa (e.g. between subspecies: Attwater's vs. greater prairie-chickens) should already be lower for the prebottleneck comparisons compared to values obtained from within-subspecies comparisons (within greater prairie-chickens), because 
isolation should have already been well established prior to the bottleneck event.

For each pairwise comparison, a minimum of two chains (length of Markov chain = 3 million cycles; burn-in = 200000 cycles) with different random seeds were run using the finite sites model (Hasegawa-Kishino-Yano [HKY], Hasegawa et al. 1985), with $M_{\max }=5,15$ or 50 , and $T_{\max }=1$ or 3 or 10 . For each pairwise comparison, values for $M_{\max }$ and $T_{\max }$ were selected that generated a bell shaped posterior distribution, but minimized the relative number of data points in the upper portion of the curve (i.e. tail). Credibility intervals were calculated for $\theta$, the effective population size scaled to the neutral mutation rate, and $M$, but not for $T$ because the upper portion of the curve for $T$ slowly decreases to zero, and therefore accurate credibility interval estimates for this measure could not be determined. Furthermore, a few estimates of $M$ using our maximum prior never quite reached zero, and consequently, their upper credibility limits were undefined $(M>50)$. Pairwise estimates of $T$ and TMRCA were converted to years before present (увг) since population divergence and gene coalescence, respectively, using an estimate for mutation rate per locus per year $\left[\mu=5.6 \times 10^{-5}\right.$ (see above) $]$. Similar to our mismatch distribution analyses, values for $N_{\text {ef }}, T$ and TMRCA were rounded to the nearest $10^{3}$ to account for uncertainty in the fossil calibration dates as reported in Drovetski (2003).

\section{Results}

\section{Estimates of genetic diversity}

All but one of the historical populations of prairie-chickens had high levels of haplotype diversity $(h$; range $=0.700$ in eastern Missouri to 1.000 in central Nebraska; Table 1). The single exception was the greater prairie-chicken population from central Michigan $(h=0.250 ;$ S.E. $=0.064)$. When we assumed that historical populations were connected by gene flow (see Johnson et al. 2003) and combined all regions as a single taxonomic population, both greater $(h=0.928$; S.E. $=0.001)$ and Attwater's $(h=0.912$; S.E. $=0.011)$ prairiechickens had high levels of haplotype diversity (Table 1). Nucleotide diversity $(\pi)$ in historical greater prairie-chicken populations ranged from 0.004 (S.E. < 0.001) in Illinois and central Michigan to 0.016 (S.E. $=0.001)$ in central Minnesota. Overall, historical populations of greater $(\pi=0.010$; S.E. $<$ 0.001) and Attwater's ( $\pi=0.009 ;$ S.E. $<0.001)$ prairie-chickens had comparable levels of nucleotide diversity (Table 1). A total of 11 and 71 unique haplotypes were observed among historical populations of Attwater's $(n=19)$ and greater ( $n=216)$ prairie-chickens, respectively (Table 1; Table S2, Supplementary material,). Forty-seven sites out of $384 \mathrm{bp}$ of sequence were variable, with 45 transitions, five transversions, and one indel for historical greater prairie-chickens, and
13 sites were variable (all transitions and no indels) for the historical population of Attwater's prairie-chicken.

Contemporary populations had a much wider range of genetic diversity $(h=0.484-0.968)$ than the majority of historical populations ( $h=0.700-1.00$; Table 1 ). Haplotype diversity in contemporary populations that have undergone severe population contractions (i.e. Illinois, Wisconsin, and Attwater's prairie-chickens) was generally low, while all nonbottlenecked contemporary populations had relatively high levels of haplotype diversity (Table 1). Compared to their corresponding historical populations, haplotype diversity estimates from contemporary bottlenecked populations were significantly lower $(P<0.001, t$-test $)$. Nucleotide diversity ranged from 0.001 (S.E. $<0.001$ ) in southeast Nebraska to 0.016 (S.E. $=0.004$ ) in Wisconsin's Paul Olson population. Contemporary populations of greater $(n=282)$ and Attwater's ( $n=36)$ prairie-chickens, had 64 and eight unique haplotypes, respectively (Table 1; Table S2, Supplementary material). Along the 384-bp of sequence, 47 sites were variable with 45 transitions, three transversions, and two indels for contemporary greater prairie-chickens, and 13 sites were variable with 12 transitions and one transversion for contemporary populations of Attwater's prairie-chickens. Previously unpublished DNA sequences used in this study were deposited in GenBank (Accession nos EF151020EF151065; see Supplementary material).

\section{Nested clade analysis}

A single network connecting all haplotypes was formed for each of the temporal analyses (historical and contemporary) using parsimonious connections in TCS (95\% connection limit; Figs 2 and 3). After resolving several ambiguous connections using frequency and topology criteria, the historical and contemporary networks were comparable in overall topology with both networks possessing the same multiple internal star-shaped nodes (haplotypes 1, 4, 7, 36, and 48). Thirty-two haplotypes were shared between the two temporal networks, and these shared haplotypes constituted a large proportion of the total number of haplotypes in each network ( $41 \%$ and $45 \%$ for the historical and contemporary networks, respectively). The placement for the majority of shared haplotypes and the connections between internal star-shaped nodes were also similar within each temporal network; however, there were a few exceptions such as the placement of haplotypes 65 and 81 and the connections between haplotypes 1 and 36, and also 36 and 48 (Figs 2 and 3). Most notably, the frequency of some shared haplotypes changed significantly between the two temporal networks (Figs 2 and 3; Table S2, Supplementary material). Compared to the contemporary network, the historical network resulted in a larger number of clades within each nesting category (i.e. one-step, two-step, etc.; see Fig. S1, Supplementary material), although 


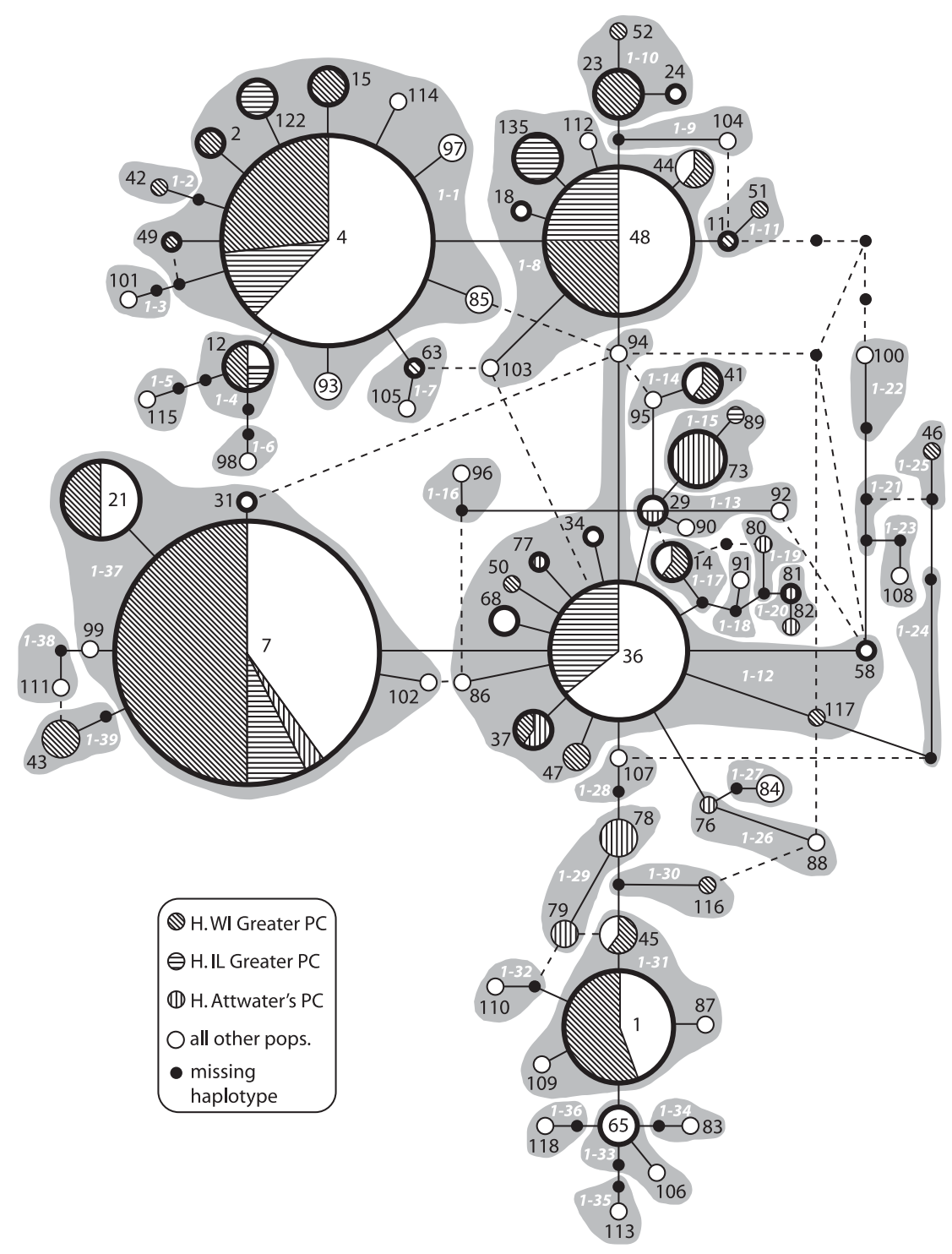

Fig. 2 Unrooted estimated 95\% parsimony network cladogram for historical prairiechicken samples. Each circle represents a single haplotype where the size of the circle is proportional to the number of individuals observed with that particular haplotype. Circles without haplotype identifying numbers represent intermediate haplotypes missing in the sample. Areas with highlighted patterns within each circle represent the frequency of samples for that particular haplotype collected from the corresponding bottlenecked populations (key provided), and circles with thicker outlines represent haplotypes identified in both temporal networks (see Fig. 3). Solid and dotted lines represent parsimonious connections between haplotypes corresponding to a single point-mutation, with dotted lines representing less probable connections (see Methods). One-step nested clades necessary for NCA are also shown. they both had the same number of nested clade levels (four steps).

There was an association between geography and haplotypes almost twice as often among contemporary than historical clades, suggesting greater differences among contemporary populations. In the historical network, $24 \%$ $(8 / 34)$ of clades with sufficient variability for testing (i.e. both genetic and geographical) showed a significant relationship between mtDNA haplotype genealogy and geographical distribution. In the contemporary network, the percentage of clades that showed a significant association between haplotypes and geography increased to $44 \%$ (14/32 of clades). To determine if this difference was simply an artefact of the smaller sample size in the historical data set, we also conducted NCA using a combined historical and contemporary data set, but excluding bottlenecked populations. The topology of this combined network was identical to that of the historical network (Fig. 2), and there was a significant association between haplotypes and geography in $21 \%(9 / 43)$ of the nested clades in the combined network, similar to that found for the historical network (24\%). This suggests that the difference in results between the historical and contemporary networks was due to the presence of bottlenecked populations in the contemporary network, and not to differences in sample size.

Inferences of demographic history from NCA were relatively similar when we compared results from the historical and combined data sets. However, inferences from the contemporary analysis differed considerably from the historical and combined analyses, particularly those related to bottlenecked populations (see Table 2). Some of these differences between data sets were appropriate as past gene flow (PGF) followed by extinction of intermediate populations was inferred in three of the nested clades within 


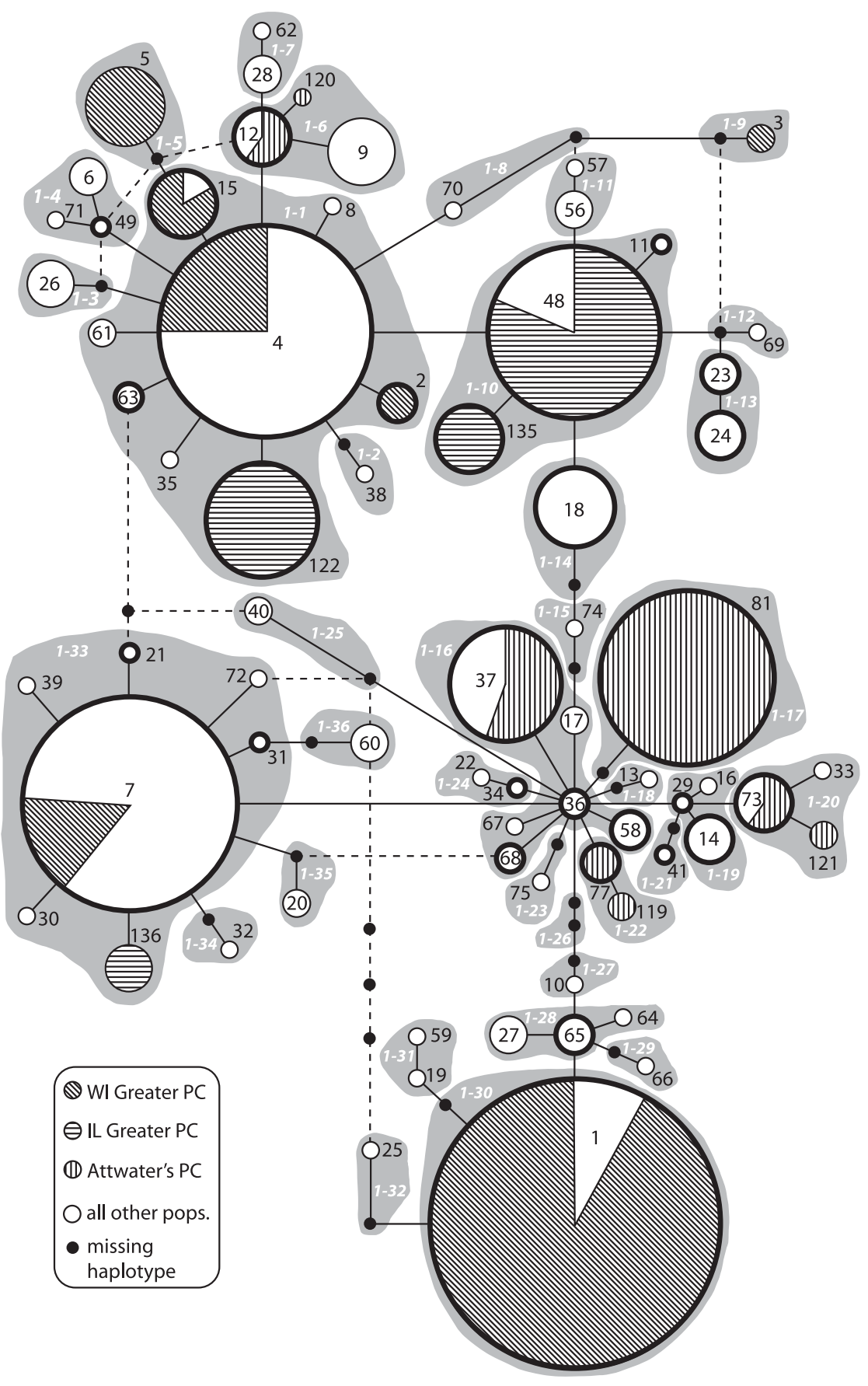

Fig. 3 Unrooted estimated 95\% parsimony network cladogram for contemporary prairie-chicken samples. See Fig. 2 legend for more details.

the contemporary analysis, but in none of the historical (or combined) analyses. For example, in the contemporary analysis, clades 1-1 and 3-3 consist of a large number of greater prairie-chicken samples from Illinois and Attwater's prairie-chicken populations, respectively (Fig. 3; Fig. S1b, Supplementary material). Therefore, PGF followed by the extinction of intermediate populations is a likely demographic scenario for these populations, which are currently isolated, but were probably connected in the past. Both clades (1-1 and 3-3) had subclades (H122 and 2-7, respectively) with significantly small $D_{c}$ and large $D_{n}$, which occurred because there was a high frequency of identical haplotypes within the two bottlenecked populations.

In contrast, NCA inferred two unlikely demographic processes associated with bottlenecked populations. Allopatric fragmentation was responsible for the association between geography and haplotypes for clade 2-7 (Fig. S3, Supplementary material); however, analysis of the comparable region within the historical network suggested that restricted gene flow (RGF) with isolation by distance (IBD) 
Table 2 Biogeographical history inferred for each nested (1- to 4-step) clade with geographical-haplotype associations using NCA. The combined data set includes both the historical and the contemporary data, but excluding data from the bottlenecked populations. Total cladograms results are not included in this table. PGF, past gene flow with extinction of intermediate populations; RGF, restricted gene flow; $\mathrm{IBD}$, isolation by distance; $\mathrm{LDD}$, long distance dispersal; $\mathrm{AF}$, allopatric fragmentation; $\mathrm{CRE}$, continuous range expansion

\begin{tabular}{|c|c|c|c|c|c|c|}
\hline Data set & PGF & RGF w/IBD & RGF w/LDD & $\mathrm{AF}$ & CRE & Inconclusive \\
\hline Historical & None & $\begin{array}{l}2-3 \\
2-7 \\
3-3\end{array}$ & $\begin{array}{l}1-8 \\
1-12\end{array}$ & None & $3-5$ & $4-1$ \\
\hline Contemporary & $\begin{array}{l}1-1 \\
3-3\end{array}$ & $\begin{array}{l}1-6 \\
1-16 \\
2-1 \\
3-2 \\
3-4 \\
4-2\end{array}$ & None & $2-7$ & $\begin{array}{l}2-4 \\
2-8 \\
2-11\end{array}$ & $\begin{array}{l}3-1 \\
4-1\end{array}$ \\
\hline Combined & None & $\begin{array}{l}1-12 \\
3-3\end{array}$ & $\begin{array}{l}1-8 \\
2-10 \\
4-2^{*}\end{array}$ & None & $3-1$ & $\begin{array}{l}1-15 \\
2-14 \\
4-1\end{array}$ \\
\hline
\end{tabular}

*cannot discriminate between LDD and IBD due to inadequate sampling design.

was a more likely explanation (clade 2-7; Fig. S2, Supplementary material). This difference in results is due to a large number of Attwater's prairie-chickens $(n=22)$ possessing unique haplotypes in the contemporary network, which decreased its $D_{c}$ values, and the presence (in the historical network) of a greater prairie-chicken haplotype sampled in Illinois (H89), which created a larger geographical range for the associated nested clade (clade 1-15; see Figs 2 and 3). Likewise, contiguous range expansion was indicated for three nested-clades (clades 2-4, 2-8 and 2-11; Table 2) that had a large proportion of samples from bottlenecked populations (Illinois, Attwater's prairie-chicken, and Wisconsin, respectively), while comparable regions for the historical and combined analyses provided different results. For example, the analysis of the combined network indicated no geographical association with haplotypes (clades 2-4, $2-8$, and 2-15) and the historical network identified RGF with IBD for two of the clades (2-3 and 2-7) and no geographical association with haplotypes for the third (clade 2-13; Figs S2, S4, Supplementary material).

Overall, clades in the contemporary network that possessed a large number of samples from bottlenecked populations (1-16, 2-1, 2-4, 2-7, 2-8, 2-11, and 3-4) typically had small $D_{\mathrm{c}}$ values, which indicates that the geographical distribution of individuals within those clades was relatively restricted. This appears to account for most of the differences in inferences of demographic history between contemporary and historical data sets.

\section{Tajima's D statistics}

The control region data generally conformed to neutral expectations, as estimates of Tajima's $D$ were not significantly different from zero in the majority of prairie-chicken populations (Table 1). The only significant exception was the contemporary Paul Olson population in Wisconsin (Table 1; see Johnson et al. 2003). Although not significant, it is important to note that all except one of the estimates of Tajima's $D$ from bottlenecked populations had positive $D$ values, while the majority of historical and contemporary populations had negative values (Table 1).

\section{Mismatch distribution analyses}

Mismatch distribution analyses indicated that almost all of the historical populations recovered the genetic signal of a sudden expansion for the species about $38000 \pm 3000$ (S.E.) увг, as Tau values ranged from 1.4 to 6.3 exhibiting unimodal distributions with low raggedness indices; however, the precision of this estimate was quite low as the confidence intervals for Tau were large for a number of populations (Table 3).

In contrast to the historical population analyses, many of the contemporary populations did not recover the genetic signal of a sudden expansion. Almost half of the studied populations $(9 / 20)$ revealed significant SSD values that rejected the sudden expansion model (all $P$ values $<0.036$ ), showing multimodal distributions that indicated either a population in demographic equilibrium or a population bottleneck (see Methods; Table 3). Consistent with theory, a large proportion of these contemporary populations have gone through documented bottleneck events, as multiple peaks at larger values were observed among the majority of mismatch distributions from these bottlenecked populations (Fig. 4), and with the exception of the contemporary population of greater prairie-chickens in Illinois, the raggedness indices from these distributions were quite large (>0.144; Table 3). 
Table 3 Mismatch distribution results for historical and contemporary prairie-chicken populations. Populations with samples sizes $<8$ individuals are not shown. Tau $(\tau)$ was converted to years before present (увг) when analysis failed to reject the sudden expansion model. C.I., confidence interval; NS, not significant $(P>0.05) ;{ }^{*}$, raggedness index $P<0.05$

\begin{tabular}{|c|c|c|c|c|c|}
\hline Sample period and population & $N$ & Tau (95\% C.I.) & увр & $\begin{array}{l}\text { SSD } \\
P \text { value }\end{array}$ & $\begin{array}{l}\text { Raggedness } \\
\text { index }\end{array}$ \\
\hline \multicolumn{6}{|l|}{ Historical populations (1854-1954) } \\
\hline Greater prairie-chicken (all pops) & 216 & $3.209(1.542-11.125)$ & 28000 & NS & 0.014 \\
\hline North Dakota-North & 13 & $3.085(1.950-11.830)$ & 27000 & NS & 0.020 \\
\hline Minnesota-central/Northwest & 19 & $4.172(1.886-13.291)$ & 37000 & NS & 0.036 \\
\hline Iowa & 8 & $6.318(2.419-20.193)$ & 56000 & NS & 0.028 \\
\hline Nebraska/South Dakota & 21 & $4.070(1.964-10.917)$ & 36000 & NS & 0.013 \\
\hline KS, NE (S.E.), MO, and OK & 15 & $1.398(0.077-7.930)$ & 12000 & NS & 0.031 \\
\hline Michigan- Upper Peninsula & 12 & $5.123(2.070-10.048)$ & 45000 & NS & 0.060 \\
\hline Michigan-central & 8 & 3.000 & - & 0.028 & 0.688 \\
\hline Michigan-Southeast & 12 & $4.123(1.562-10.757)$ & 37000 & NS & 0.021 \\
\hline Michigan-Southeast/central & 20 & $5.895(1.942-14.145)$ & 52000 & NS & 0.083 \\
\hline Illinois-North/South & 24 & $2.977(1.333-5.804)$ & 26000 & NS & 0.038 \\
\hline Wisconsin-Mead & 18 & $3.190(1.294-9.362)$ & 28000 & NS & 0.011 \\
\hline Wisconsin-Paul Olson & 19 & $4.762(2.219-8.114)$ & 42000 & NS & 0.042 \\
\hline Wisconsin-Buena Vista & 19 & $5.884(2.757-10.122)$ & 52000 & NS & 0.056 \\
\hline Wisconsin-Leola & 17 & $6.207(2.447-11.301)$ & 55000 & NS & 0.038 \\
\hline Attwater's prairie-chicken & 19 & $4.237(2.167-6.620)$ & 38000 & NS & 0.036 \\
\hline Colorado Co & 10 & $4.607(2.194-7.773)$ & 41000 & NS & 0.041 \\
\hline \multicolumn{6}{|l|}{ Contemporary populations (1974-2001) } \\
\hline Greater prairie-chicken (all pops) & 282 & $4.183(2.102-15.534)$ & 37000 & NS & 0.010 \\
\hline Greater prairie-chicken (no WI/IL) & 170 & $4.016(2.460-7.836)$ & 36000 & NS & 0.022 \\
\hline Minnesota-Northwest & 20 & $4.007(1.742-7.102)$ & 36000 & NS & 0.097 \\
\hline Minnesota-West central & 20 & 4.019 & - & 0.018 & $0.094^{*}$ \\
\hline South Dakota-central & 20 & $4.971(2.718-6.862)$ & 44000 & NS & 0.023 \\
\hline Nebraska-North & 20 & $2.637(1.275-6.747)$ & 23000 & NS & 0.014 \\
\hline Nebraska-central & 20 & $3.733(1.624-5.320)$ & 33000 & NS & 0.022 \\
\hline Nebraska-Southeast & 20 & $1.202(0.000-10.530)$ & 11000 & NS & 0.022 \\
\hline Kansas-East central & 20 & $5.390(2.295-10.631)$ & 48000 & NS & 0.038 \\
\hline Missouri-Southwest & 20 & 6.032 & - & $<0.001$ & $0.240^{*}$ \\
\hline Oklahoma-Northwest & 10 & $6.884(3.213-11.173)$ & 61000 & NS & 0.034 \\
\hline \multicolumn{6}{|l|}{ Bottlenecked populations } \\
\hline Illinois-South & 32 & $3.056(0.912-7.347)$ & 27000 & NS & 0.045 \\
\hline Wisconsin-Mead & 20 & 6.000 & - & 0.030 & 0.487 \\
\hline Wisconsin-Paul Olson & 20 & 12.292 & - & $<0.001$ & $0.318^{*}$ \\
\hline Wisconsin-Buena Vista & 20 & $6.000(1.765-10.672)$ & 53000 & NS & 0.317 \\
\hline Wisconsin-Leola & 20 & 9.354 & - & 0.008 & $0.222^{*}$ \\
\hline Attwater's prairie-chicken & 36 & 4.764 & - & 0.036 & $0.134^{*}$ \\
\hline Refugio County & 10 & 6.000 & - & 0.008 & 0.720 \\
\hline Colorado County & 13 & 4.271 & - & 0.034 & 0.144 \\
\hline Galveston County & 13 & 4.375 & - & 0.004 & $0.461^{*}$ \\
\hline
\end{tabular}

\section{MDIV analyses}

Estimates of effective population size $\left(\theta\right.$ and $\left.N_{\mathrm{ef}}\right)$, divergence time $(t)$, and TMRCA were similar before and after bottlenecks, as credibility intervals (C.I.) for $\theta$ overlapped considerably (Table 4). Similar results were observed when we combined the historical greater prairie-chicken samples as a single population (data not shown), or used sampling locations to define contemporary populations of nonbottlenecked prairie-chickens (e.g. Nebraska-North; see Fig. 5) to conduct pairwise comparisons between pre- and post-bottlenecked populations.

In contrast, estimates of $M$ between populations of greater prairie-chickens (within subspecies) were consistently lower after bottlenecks than before them (Table 4). Prior to the recent bottleneck, $M$ was 28.4 (C.I. $=8.7$ - undefined) between Wisconsin populations and other greater prairiechicken populations (nonbottleneck contemporary), but the value decreased to $1.7(0.7-4.0)$ after the bottleneck (Table 4, Fig. 5b, c). Similarly, gene flow in Illinois decreased 

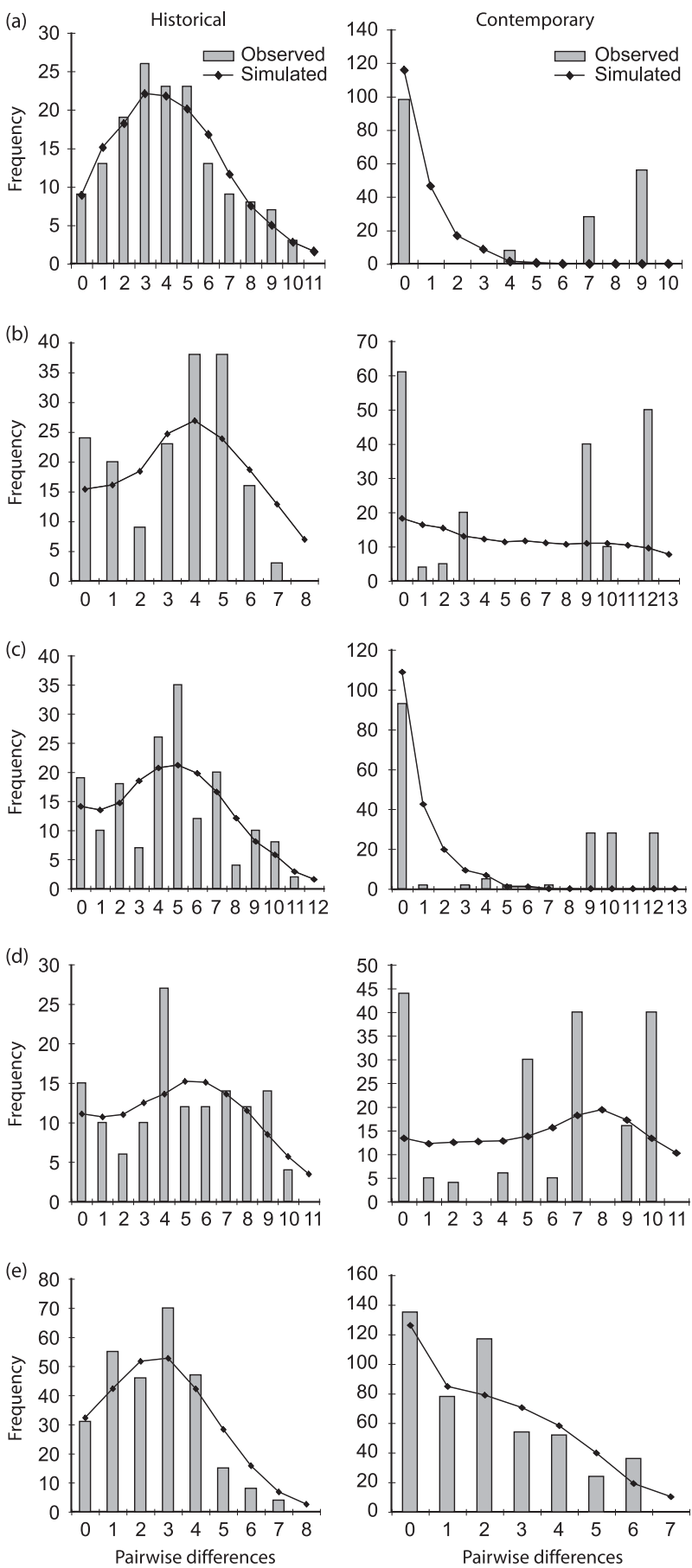

Fig. 4 Mismatch distributions for historical (left column) and contemporary (right column) greater prairie-chicken populations from Wisconsin's (a) Mead (b) Paul Olson (c) Buena Vista, and (d) Leola management areas, and (e) Illinois.

from 10.1 (5.5 to 31.1) before the bottleneck to 0.8 (0.2-2.2) after the bottleneck. Again, these results were also similar when analyses were conducted using the combined historical greater prairie-chicken samples (data not shown) or the individual nonbottlenecked contemporary greater prairie- chicken populations (Fig. 5b,c). For Attwater's and greater prairie-chicken population comparisons (i.e. between subspecies), estimates of gene flow were similar before and after bottlenecks, and the values were consistently lower $(<4.0)$ than those from within-subspecies comparisons (Table 4). For TMRCA, estimates were similar between preand post-bottleneck comparisons for both greater and Attwater's prairie-chickens with values ranging from 89000 to 105000 yвP when using the contemporary nonbottlenecked populations (Table 4).

\section{Discussion}

In this study, we examined the ability of phylogenetic and coalescent methods to reconstruct the demographic history of populations sampled in both historical (1854-1954) and contemporary (primarily 1997-2001) periods. We were particularly interested in the performance of these methods before and after well-documented population bottlenecks and episodes of fragmentation. Depending on the severity and longevity of a bottleneck, unique alleles may become fixed in populations with recent common ancestry, and as a consequence, historical information about lineages may be lost. This occurred in our Wisconsin populations separated by 50 years, and it could have led to incorrect conclusions about demography and phylogeography if we did not have data available from historical populations (see also Johnson \& Dunn 2006). In cases such as these, methods that can detect recent bottleneck events or identify historical demographic processes in spite of recent bottlenecks are particularly valuable. Of the methods examined here, we found that the accuracy of inferences made by NCA was influenced the most by changes in the frequency of haplotypes, as occurs following a demographic bottleneck. Coalescent and summary statistic methods, such as MDIv, Tajima's $D$ and the mismatch distribution, were all more likely to either identify populations that have experienced bottlenecks or provide similar results from populations before and after a bottleneck. In spite of their differences, each method has its advantages and disadvantages, which we discuss below in more detail.

\section{Nested clade analysis}

A number of recent studies have documented inconsistencies produced by NCA when using both empirical and simulated data sets (Knowles \& Maddison 2002; Paulo et al. 2002; Masta et al. 2003; Smith \& Farrell 2005; but see Templeton 2004). To date, the effects of bottlenecks have not been considered when making demographic inferences from empirical data sets using this method. Although NCA with our data sets recovered historical signals of restricted gene flow (see historical analysis; Table 2) and some contemporary signals of past gene flow with extinction of intermediate 
Table 4 Pairwise estimates of theta $(\theta)$, female effective population size $\left(N_{\mathrm{ef}}\right)$, gene flow $(M)$, and times (yвP) since population divergence $(t)$ and time to the most recent common ancestor (TMRCA) for greater and Attwater's prairie-chicken populations based on mtDNA control region data using the program MDIV. Parameters were estimated between nonbottlenecked contemporary populations of greater prairiechickens (GPC nonbottlenecked) and a Wisconsin or Illinois greater prairie-chicken or Attwater's prairie-chicken population (sampled either before or after a recent bottleneck). Values shown are those with the highest posterior probability scores for $\theta, M$, and $T$, and $95 \%$ credibility intervals (C.I.) are provided for estimates of $\theta$ and $M$. udf, undefined $(M>50)$

\begin{tabular}{|c|c|c|c|c|c|}
\hline Population comparisons & $\theta[95 \%$ C.I. $]$ & $N_{\mathrm{ef}}$ & $M[95 \%$ C.I.] & $t$ (увр) & TMRCA (увг) \\
\hline \multicolumn{6}{|c|}{ Wisconsin GPC vs. GPC nonbottlenecked } \\
\hline \multicolumn{6}{|c|}{ Prebottleneck } \\
\hline Paul Olson & $12.2[8.8-16.4]$ & 108000 & $15.2[12.0-\mathrm{udf}]$ & 8000 & 94000 \\
\hline Mead & $11.3[8.5-15.8]$ & 100000 & $26.0[12.3-u d f]$ & 1000 & 92000 \\
\hline Buena Vista & $11.4[8.7-16.1]$ & 101000 & 32.7 [18.1-udf] & 3000 & 92000 \\
\hline Leola & $12.0[8.9-16.8]$ & 106000 & $42.2[20.6-\mathrm{udf}]$ & 4000 & 95000 \\
\hline Combined & $12.1[9.0-16.4]$ & 108000 & $28.4[8.7-\mathrm{udf}]$ & 5000 & 92000 \\
\hline \multicolumn{6}{|l|}{ Post-bottleneck } \\
\hline Paul Olson & $12.6[9.0-17.6]$ & 111000 & $3.4[2.2-36.8]$ & 14000 & 98000 \\
\hline Mead & $10.8[8.1-15.8]$ & 96000 & $22.8[6.4-41.4]$ & 7000 & 90000 \\
\hline Buena Vista & $13.9[9.8-19.1]$ & 124000 & $1.7[0.5-13.3]$ & 7000 & 105000 \\
\hline Leola & $12.2[8.9-16.5]$ & 108000 & $19.3[9.9-47.3]$ & 3000 & 95000 \\
\hline Combined & $10.9[8.1-15.1]$ & 97000 & $1.7[0.7-4.0]$ & 13000 & 102000 \\
\hline \multicolumn{6}{|c|}{ Illinois GPC vs. GPC nonbottlenecked } \\
\hline Prebottleneck & $12.0[9.3-16.9]$ & 107000 & $10.1[5.5-31.1]$ & 14000 & 90000 \\
\hline Post-bottleneck & $13.1[9.6-18.1]$ & 116000 & $0.8[0.2-2.2]$ & 21000 & 93000 \\
\hline \multicolumn{6}{|c|}{ Attwater's PC vs. GPC nonbottlenecked } \\
\hline Prebottleneck & $14.7[10.8-20.7]$ & 130000 & $2.5[1.3-9.3]$ & 33000 & 89000 \\
\hline \multicolumn{6}{|l|}{ Post-bottleneck } \\
\hline Colorado County & 15.5 [11.5-21.6] & 137000 & $0.8[0.2-2.9]$ & 34000 & 90000 \\
\hline Galveston County & $14.2[10.6-20.7]$ & 126000 & $2.3[0.4-7.8]$ & 20000 & 91000 \\
\hline Refugio County & 13.6 [10.1-19.6] & 121000 & 3.9 [1.9-24.6] & 19000 & 90000 \\
\hline
\end{tabular}

populations (see contemporary analysis; Table 2), demographic inferences changed considerably depending on the recent history of specific clades under consideration. These differences were likely due to the presence of bottlenecked populations in the analysis, which were revealed by the historical analysis and by excluding the bottlenecked populations in the combined analysis (Table 2). However, we still cannot rule out completely that some of the differences may be due to sampling artefacts, rather than just bottleneck events. Sampling issues will always be an issue with NCA as it requires that all extant populations are sampled.

The effects of bottlenecks were also evident in the initial steps of the NCA because almost half as many clades in the historical and combined analyses showed no association between haplotypes and geography than in the contemporary analysis. These results are not unexpected because greater prairie-chickens were an abundant grassland bird at the beginning of the 20th century and panmixia or isolation by distance is a likely description of their historical distribution (see Johnson et al. 2003). Today, populations that were once contiguous have declined in size and become highly fragmented throughout much of their range. The effects of localized population contractions, isolation, and extinction appear therefore to have influenced the clade distance measures $\left(D_{\mathrm{c}^{\prime}} D_{\mathrm{n}}\right.$ and $\left.\mathrm{I}-\mathrm{T}\right)$ and network topology, and consequently, the demographic inferences made by NCA.

In a previous study using NCA and an older version of its inference key, Masta et al. (2003) observed several cases of long-distance dispersal and colonization in a North American toad (Bufo woodhousii), which was an unlikely scenario considering the low vagility of this species. Instead, Masta et al. (2003) suggested that these cases were more likely due to the extinction of haplotypes in intermediate geographical areas (see also Paulo et al. 2002). Both of these population processes (dispersal and extinction) can produce shorter clade distance $\left(D_{c}\right)$ values and longer nested clade distances $\left(D_{\mathrm{n}}\right)$ within a particular clade. The $D_{\mathrm{c}}$ values measure the geographical range of a particular haplotype group, or clade, and $D_{\mathrm{n}}$ values measure how a haplotype group is distributed relative to all of the haplotypes present in the overall nested group. Subsequently, an updated inference key (Templeton 2004) was provided that included the possibility of extinctions in intermediate areas. However, the revised key required knowledge of the historical distribution of the species, particularly within these intermediate areas (step 8), the dispersal ability of the organism, and inferences made by other methods such as mismatch distributions (step 21). 

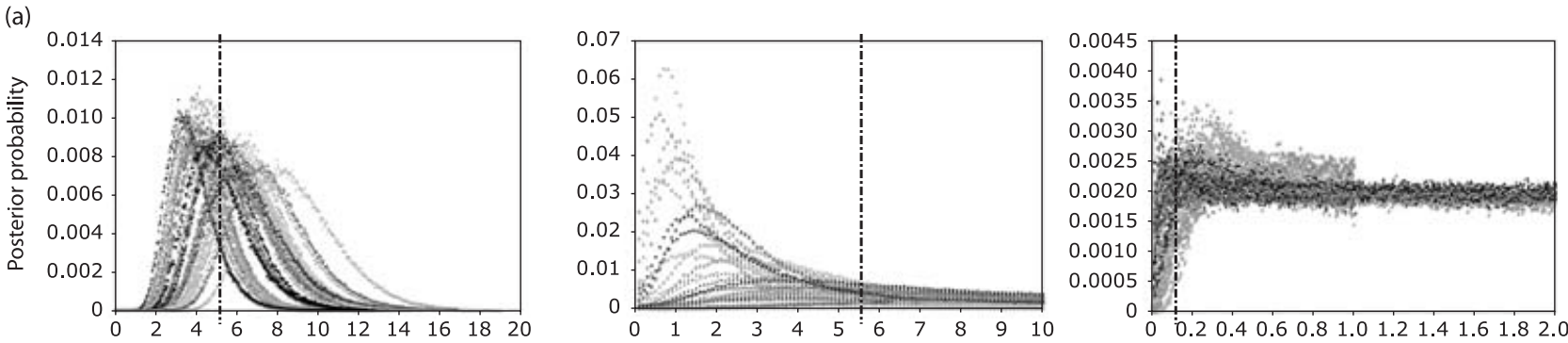

(b)
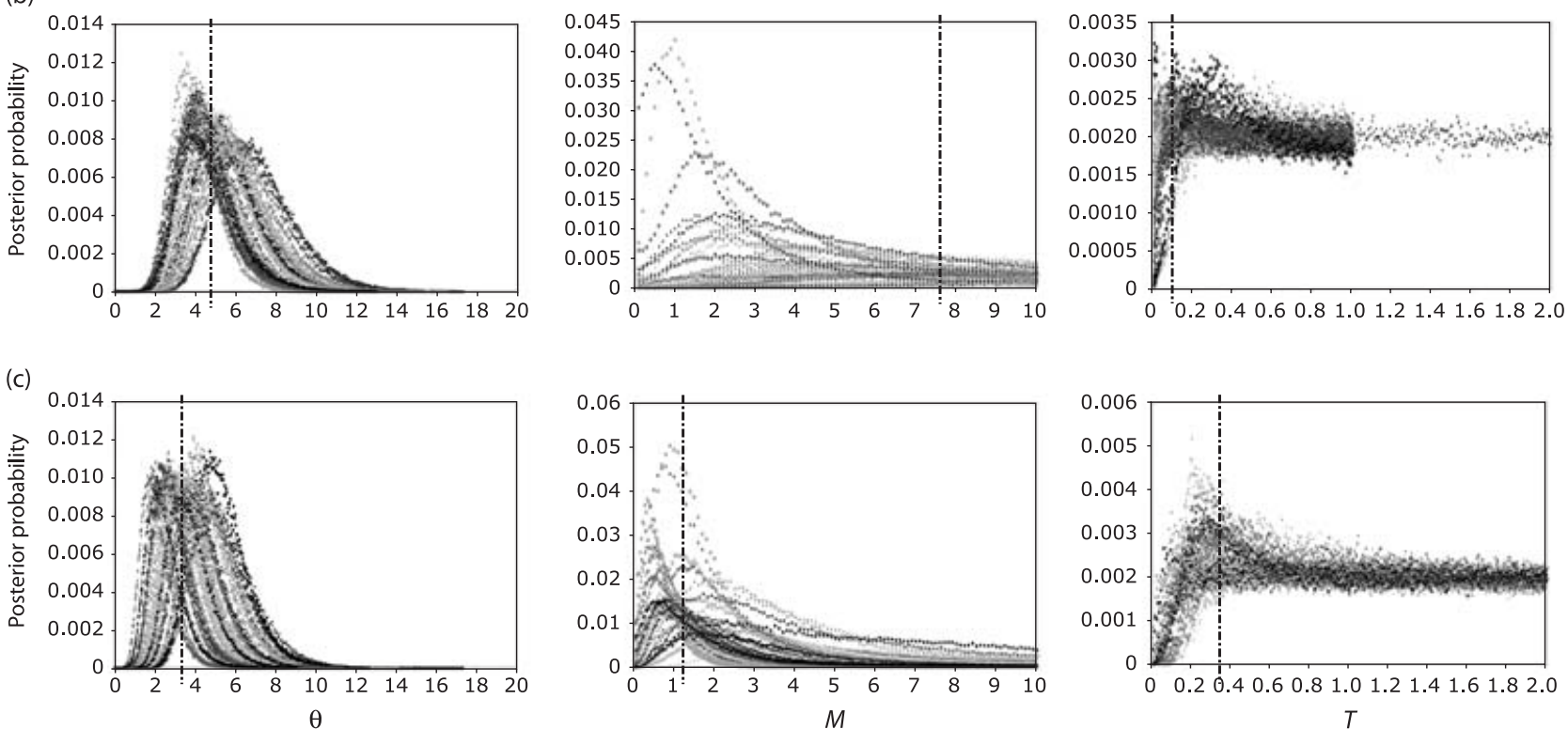

Fig. 5 MDIV posterior distributions of greater prairie-chicken population pairwise estimates of $\theta, M$, and $T$ between (a) contemporary nonbottlenecked populations, (b) historical prebottlenecked Wisconsin and contemporary nonbottlenecked populations, and (c) contemporary post-bottlenecked Wisconsin and nonbottlenecked populations. Vertical dotted line indicates mean estimate for each parameter.

We observed a number of clades possessing a large number of individuals from bottlenecked populations with significantly small $D_{\mathrm{c}}$ values and relatively large $D_{\mathrm{n}}$ values, similar to Masta et al. (2003). The inferences from these clades were that the association between haplotypes and geography was caused by past gene flow followed by extinction of intermediate populations. However, we also observed a number of interior clades (as opposed to tip clades; see Methods) possessing both significantly small $D_{\mathrm{c}}$ and $D_{\mathrm{n}}$ values, and the inference for these clades was contiguous range expansion. These clade distance values were clearly influenced by a large number of individuals possessing the same haplotypes from bottlenecked populations. It is not surprising to observe a decline in $D_{c}$ values when a large proportion of individuals possess the same haplotypes due to a bottleneck event and the loss of genetic variability, and such cases should be taken into consideration when performing NCA.

Overall, although NCA seemed to recover historical signals of demographic processes for some clades, it was unable to identify signals of recent bottlenecks from contemporary populations. Currently, NCA does not account for the effects of bottleneck events and therefore its inference is not included in the key. A major limitation of NCA is that, in many cases, demographic inferences changed considerably depending on the recent history of the clade/ population under consideration. Consequently, demographic and genetic processes such as population bottlenecks and genetic drift could lead to incorrect decisions concerning the taxonomic status (Wiens \& Penkrot 2002; Sites \& Marshall 2004) and management (Palkovacs et al. 2004; Johnson \& Dunn 2006) of species.

Coalescent-based methods that estimate specific population genetic parameters can potentially circumvent some of these limitations because they do not place as much emphasis on single gene trees, and they also allow testing of alternative historical models with explicit statistical methods (Knowles \& Maddison 2002; Rosenberg \& Nordborg 2002; Hey \& Machado 2003; Knowles 2004). In fact, Templeton (2004) acknowledged that 'false inferences can arise 
from the evolutionary stochasticity of the coalescent process itself, from the haplotype tree being skewed ..., or from inadequacies in NCA and/or its inference key.'

\section{Tajima's D}

In this study, the majority of Tajima's $D$ values among prairie-chicken populations were not significantly different from zero. However, in the single significant case, the value was positive and corresponded with a bottlenecked population (i.e. the Paul Olson population in Wisconsin; Table 1). Significance in this case was more likely due to the recent demographic bottleneck, rather than population subdivision or a selective sweep (see also Fay \& Wu 1999; Depaulis et al. 2003; Johnson et al. 2004). The remainder of bottlenecked populations had a consistent trend toward positive $D$ values, with the exception of the population of Attwater's prairiechickens in Galveston County (Table 1). In all of these cases, a severe population contraction has been well documented prior to sampling (Westemeier et al. 1998; Johnson et al. 2004; Silvy et al. 2004), which suggests that Tajima's D can be useful for documenting recent bottlenecks (see also Glenn et al. 1999). However, these conclusions should be tested further as the power to detect deviations from neutral expectations using Tajima's $D$ is limited and depends on a number of factors, including sample size, length of sequence data, the timing of sampling relative to a demographic event, and the strength of the actual event (Simonsen et al. 1995; Depaulis et al. 2003; Pannell 2003).

\section{Mismatch distribution and sudden expansion events}

The majority of historical and contemporary prairie-chicken populations that had not experienced a bottleneck failed to reject a model of sudden expansion occurring in the Late Pleistocene. This result is not unexpected given the glacial history of North America and similar results from other recent studies (Ross et al. 2006; Spaulding et al. 2006). In contrast, the model of sudden expansion was rejected for most populations that had experienced a bottleneck (Table 3). There were a few exceptions, such as the contemporary Buena Vista population in Wisconsin; however, the distribution of pairwise nucleotide differences appeared multimodal at Buena Vista, especially when compared to its historical distribution (Fig. 4c), and it possessed a high raggedness index $(r=0.317)$ with many peaks at large values and a large number of individuals with identical haplotypes (i.e. low genetic variability). These same characteristics were shared with all bottlenecked populations, even when a few of these populations had relatively high haplotype diversity (e.g. Leola in Wisconsin: $h=0.784$ and Attwater's prairie-chicken in Colorado County: $h=0.833$ ). Similar results were found by Weber et al. (2004) who reported a multimodal distribution of pairwise nucleotide differences in a population of Guadalupe fur seals (Arctocephalus townsendi) following a demographic bottleneck (see also Bernatchez 2001).

Theoretical expectations of mismatch distributions have been previously evaluated (Slatkin \& Hudson 1991; Rogers \& Harpending 1992; Harpending et al. 1998), although they have not been empirically tested due to the lack of historical and contemporary samples from populations with known demographic histories. In particular, there is no empirical evidence of the effects of declining populations, substructure, or inbreeding on the shape of mismatch distributions (Schneider \& Excoffier 1999). According to Rogers \& Harpending (1992), 'bottlenecks should often generate ragged empirical distributions with many peaks at large values' giving the appearance of a multimodal distribution. This should cause the test statistic to reject the null hypothesis of sudden expansion, yet the alternative hypothesis, demographic equilibrium, is clearly incorrect in this situation. The degree to which a population bottleneck will influence these results should depend on the severity of contraction and its duration (Harpending et al. 1998). Thus, our study and Weber et al. (2004), provide empirical evidence that genetic signals of recent population declines can be detected using mismatch distributions and they may not necessarily be masked by earlier demographic events (cf. Lavery et al. 1996).

\section{MDIV analyses of isolation and migration}

The coalescent-based program MDIV provided estimates of effective population size ( $\theta$ and $N_{\mathrm{ef}}$ ), divergence time $(t)$ and TMRCA that were variable, but largely robust to the effects of recent population bottlenecks (95\% credibility intervals overlapped in most cases before and after bottlenecks). This suggests that our estimates reflect demographic processes largely occurring hundreds to thousands of generations ago (see also Johnson et al. 2003, 2004; Johnson \& Dunn 2006). The variation in our point estimates is expected as a consequence of several sources of stochasticity, including stochastic processes within the genealogy itself, mutations during sequence evolution, and sampling of populations (Edwards \& Beerli 2000; Nielsen \& Wakeley 2001; Knowles 2004; Hein et al. 2005). Nonetheless, point estimates of gene flow $(M)$ were consistently lower after the bottleneck than before it in the Wisconsin and Illinois populations, but not in comparisons between Attwater's and greater prairiechicken populations. This difference might be expected given that isolation between these two subspecies should have been well established prior to the bottleneck event in Attwater's prairie-chicken populations.

The effects of bottlenecks on accurate estimates of demographic parameters will depend on the severity of the bottleneck, including its longevity. During a bottleneck, the rate of coalescence should increase within a population because the likelihood of sampling the same haplotype will 
increase as the effective population size is reduced (Hein et al. 2005). Lineages within a population may actually coalesce during the bottleneck, producing a shallower genealogy. Lineages will be more likely to survive a population bottleneck if the contraction is not as severe (i.e. $N_{\mathrm{e}}$ is larger). These populations should take longer to coalesce and have longer external branches in the genealogy, often causing Tajima's $D$ to be positive if sampling occurred soon after, or during, the bottleneck event (see Hein et al. 2005). However, given the randomness associated with genetic drift and the increased variance associated with the bottleneck event itself, results are likely to vary for all parameters, including $M$, when population comparisons are made with methods such as MDIV. This variation was evident in the estimates from our Wisconsin comparisons (see Table 4). Therefore, specific inferences related to population divergence time and isolation should be made with caution, particularly when the populations under consideration have experienced recent demographic contractions.

Overall, the effects of recent bottlenecks on these analyses did not change our conclusions about the demographic history of the greater prairie-chicken: populations show evidence of recent connectivity and gene flow throughout their range. Genetic similarities between populations were not due primarily to incomplete lineage sorting, as estimates of $M$ were relatively high in the majority of cases and population divergence times were much more recent than the TMRCA. In fact, migration $(M)$ was related negatively and population divergence time $(t)$ was related positively to geographical distance when comparing individual populations of both greater and Attwater's prairie-chickens $(P<0.05$; Mantel tests with 10000 permutations; data not shown). These results, which suggested isolation by distance (IBD) among populations, were not influenced by the inclusion of bottlenecked populations (see also Johnson et al. 2003). It should be noted that the bottlenecked populations used in this study were located on the periphery of the geographical range separated from the majority of extant populations (Fig. 1), and thus, it is not clear how our results, especially for $M$, might have differed if the bottlenecked populations were in the centre of the range and geographically closer to other populations.

When ancestral haplotypes persist in populations, it is difficult to determine whether populations differ because of differences in the levels of isolation or migration (Templeton et al. 1995; Nielsen \& Wakeley 2001; Wakeley 2004). Populations with larger ancestral $N_{\mathrm{e}}$ require more time to reach reciprocal monophyly than populations with smaller $N_{\mathrm{e}}$ (Hudson \& Coyne 2002; Hudson \& Turelli 2003; Rosenberg 2003). Therefore, a given level of population differentiation may be due to an ancient divergence followed by more recent exchange of genes or it may simply reflect a recent divergence with little subsequent gene flow. In addition, it is not known to what extent other demographic processes such as bottleneck events may affect our interpretation of the data.

From this study, it is evident that recent bottleneck events can have a substantial effect on accurate estimates of demographic history, with some methods being affected more than others. If a bottleneck event is severe enough to alter the distribution of haplotypes within a network, NCA can provide misleading results. This method is dependent on a single gene tree and currently does not take into account the effects of recent bottleneck events on estimates of demographic history, let alone the stochastic variance associated with the generation of a gene tree itself. Others have also noted that NCA does not provide any statistical approach for comparing among alternative hypotheses, and therefore it can lead to false inferences depending on the data (see Knowles \& Maddison 2002; Hey \& Machado 2003; Knowles 2004). Alternatively, methods such as those based on summary statistics (Tajima's D and mismatch distribution) allow a more objective approach using inferential statistics. As shown with this study, Tajima's $D$ and mismatch distribution can also be affected by recent bottleneck events. While mismatch distribution and its raggedness index was more likely to identify populations that had recently declined, the power to detect bottlenecks with Tajima's $D$ was limited with this data set.

The accurate assessment of demographic parameters, such as those estimated by MDIV, is particularly relevant in populations that have contracted during Pleistocene glaciation and then expanded into current populations with large effective sizes where ancestral polymorphisms persist (Griswold \& Baker 2002; Bulgin et al. 2003; Brito 2005; Peters et al. 2005; Omland et al. 2006). Bottleneck events did not dramatically affect our overall interpretation of population divergence time and TMRCA when using MDIV; however, some estimates of migration differed between population comparisons before and after bottleneck events. This result emphasizes the stochastic nature associated with the coalescent process and the difficulty associated with making accurate inferences of demography when using a single locus. More work is needed to determine how results differ among bottlenecked populations when using multiple loci (e.g. Carstens \& Knowles 2007), including those from simulated data sets (e.g. Chan et al. 2006).

\section{Conservation implications}

From a conservation perspective, accurate estimates of demographic history are important for management, yet researchers may be misled, especially if very little is known about the history of the species under consideration. This issue is especially important because many populations are changing in size and distribution as humans alter their habitat. In North America, for example, prairie grasslands 
are one of the most altered habitats by humans. Less than $10 \%$ of pre-European prairie habitat exists, and most have become highly fragmented and isolated (Samson \& Knopf 1994; Samson et al. 2004). As a result, contemporary populations of prairie-chickens have been subjected to significant reductions in population size (demographic bottlenecks), increased isolation, and population extinction.

Indeed, the Attwater's prairie-chicken is one of the most endangered birds in North America with less than 50 individuals in the wild. Managers are considering outcrossing Attwater's prairie-chickens with greater prairie-chickens to increase reproductive success (Silvy et al. 2004; M. Morrow and T. Rossignol, personal communication 2005). For these types of management programs, it is important to know the level of genetic differentiation between populations, including divergence times and gene flow. Our MDIV analyses indicate that Attwater's prairie-chickens are isolated from other populations and this isolation is not recent, as estimates of gene flow were low both before (2.5) and after (0.8-3.9) the current population decline. Overall, we found that recent population bottlenecks, increased isolation, and population extinction can have a strong influence on the results given by commonly used methods for inferring demographic history. Reliable estimates of demographic history are essential for the conservation of natural populations. In many cases, there may not be any information about recent changes in the size and level of isolation of populations, so we suggest using caution when assessing the demographic history of contemporary populations that occur in fragmented landscapes.

\section{Acknowledgements}

We thank John Toepfer and Markus Peterson for providing contemporary samples, and the United States National Museum of Natural History, American Museum of Natural History, The Field Museum, University of California-Berkeley Museum of Vertebrate Zoology, University of Michigan Museum of Zoology, University of Kansas Natural History Museum, Cornell University Museum of Vertebrates, University of Missouri-Columbia, Illinois Natural History Survey, and Texas A \& M University for providing samples from museum specimens. Linda Whittingham, Barb Wimpee, and Sergei Drovetski provided assistance and advice in the laboratory. Michael Sorenson, Bryan Carstens, John Dallas, and four anonymous reviewers provided helpful comments on the manuscript. Financial support was provided to J. J. and P.D. by the National Science Foundation, the Society of Tympanuchus Cupido Pinnatus, the Zoological Society of Milwaukee County, and the American Ornithologists' Union.

\section{References}

Arbogast BS, Edwards SV, Wakeley J, Beerli P, Slowinski JB (2002) Estimating divergence times from molecular data on phylogenetics and population genetic timescales. Annual Review of Ecology and Systematics, 33, 707-740.
Avise JC (2004) Molecular Markers, Natural History, and Evolution, 2nd edn. Sinauer Associates, Sunderland, Massachusetts.

Bellinger MR, Johnson JA, Toepfer JE, Dunn PO (2003) Loss of genetic variation in greater prairie chickens following a population bottleneck in Wisconsin, U.S.A. Conservation Biology, 17, 717-724.

Bernatchez L (2001) The evolutionary history of brown trout (Salmo trutta L.) inferred from phylogeographic, nested clade, and mismatch analyses of mitochondrial DNA variation. Evolution, 55, 351-379.

Bouzat JL, Cheng H, Lewin HA, Westemeier RL, Brawn JD, Paige KN (1998a) Genetic evaluation of a demographic bottleneck in the greater prairie-chicken. Conservation Biology, 12, 836-843.

Bouzat JL, Lewin HA, Paige KN (1998b) The ghost of genetic diversity past: historical DNA analysis of the greater prairie chicken. American Naturalist, 152, 1-6.

Brito PH (2005) The influence of Pleistocene glacial refugia on tawny owl genetic diversity and phylogeography in western Europe. Molecular Ecology, 14, 3077-3094.

Bulgin NL, Gibbs HL, Vickery P, Baker AJ (2003) Ancestral polymorphisms in genetic markers obscure detection of evolutionarily distinct populations in the endangered Florida grasshopper sparrow (Ammodramus savannarum floridanus). Molecular Ecology, 12, 831-844.

Carstens BC, Knowles L (2007) Shifting distributions and speciation: species divergence during rapid climate change. Molecular Ecology, 16, 619-627.

Castelloe J, Templeton AR (1994) Root probabilities for intraspecific gene trees under neutral coalescent theory. Molecular Phylogenetics and Evolution, 3, 102-113.

Chan YL, Anderson CNK, Hadly EA (2006) Bayesian estimation of the timing and severity of a population bottleneck from ancient DNA. Public Library of Science Genetics, 2, e59.

Clement M, Posada D, Crandall KA (2000) Tcs: a computer program to estimate gene genealogies. Molecular Ecology, 9, 1657-1659.

Crandall KA (1996) Multiple interspecies transmissions of human and simian T-cell leukemia/lymphoma virus type I sequences. Molecular Biology and Evolution, 13, 115-131.

Crandall KA, Templeton AR (1993) Empirical tests of some predictions from coalescent theory with applications to intraspecific phylogeny construction. Genetics, 134, 959-969.

Dawson AG (1992) Ice Age Earth: Late Quaternary Geology and Climate. Routledge Press, London.

Depaulis F, Mousset S, Veuille M (2003) Power of neutrality tests to detect bottlenecks and hitchhiking. Journal of Molecular Evolution, 57, S190-S200.

DeSalle R, Amato G (2004) The expansion of conservation genetics. Nature Reviews Genetics, 5, 702-712.

Dimcheff DE, Drovetski SV, Mindell DP (2002) Phylogeny of Tetraoninae and other galliform birds using mitochondrial $12 S$ and ND2 genes. Molecular Phylogenetics and Evolution, 24, 203215.

Drovetski SV (2002) Molecular phylogeny of grouse: individual and combined performance of W-linked, autosomal, and mitochondrial loci. Systematic Biology, 51, 930-945.

Drovetski SV (2003) Plio-Pleistocene climatic oscillations, Holarctic biogeography and speciation in an avian subfamily. Journal of Biogeography, 30, 1173-1181.

Edwards SV, Beerli P (2000) Perspective: gene divergence, population divergence, and the variance in coalescence time in phylogeographic studies. Evolution, 54, 1839-1854. 
Emerson BC, Paradis E, Thébaud C (2001) Revealing the demographic histories of species using DNA sequences. Trends in Ecology and Evolution, 16, 707-716.

Excoffier L, Laval G, Schneider S (2005) ARLEQUIN, version 3.0: an integrated software package for population genetics data analysis. Evolutionary Bioinformatics Online, 1, 47-50.

Excoffier L, Smouse PE (1994) Using allele frequencies and geographic subdivision to reconstruct gene trees within a species: molecular variance parsimony. Genetics, 136, 343-359.

Fay JC, Wu CI (1999) A human population bottleneck can account for the discordance between patterns of mitochondrial versus nuclear DNA variation. Molecular Biology and Evolution, 16, 1003-1005.

Gaggiotti OE, Excoffier L (2000) A simple method of removing the effect of a bottleneck and unequal population sizes on pairwise genetic distances. Proceedings of the Royal Society of London Series $B, 267,81-87$.

Glenn TC, Stephan W, Braun MJ (1999) Effects of a population bottleneck on whooping crane mitochondrial DNA variation. Conservation Biology, 13, 1097-1107.

Griswold CK, Baker AJ (2002) Time to the most recent common ancestor and divergence times of populations of common chaffinches (Fringilla coelebs) in Europe and North Africa: insights into Pleistocene refugia and current levels of migration. Evolution, 56, 143-153.

Harpending HC (1994) Signature of ancient population growth in a low-resolution mitochondrial DNA mismatch distribution. Human Biology, 66, 591-600.

Harpending HC, Batzer MA, Gurven M, Jorde LB, Rogers AR, Sherry ST (1998) Genetic traces of ancient demography. Proceedings of the National Academy of Sciences, USA, 95, 1961-1967.

Harpending HC, Sherry ST, Rogers AR, Stoneking M (1993) Genetic structure of ancient human populations. Current Anthropology, 34, 483-496.

Hasegawa M, Kishino H, Yano T (1985) Dating of the human-ape splitting by a molecular clock of mitochondrial DNA. Journal of Molecular Evolution, 21, 160-174.

Hedrick PW (2004a) Recent developments in conservation genetics. Forest Ecology and Management, 197, 3-19.

Hedrick PW (2004b) Conservation biology: the impact of population biology and a current perspective. In: The Evolution of Population Biology (eds Singh RS, Uyenoyama MK), pp. 347-365. Cambridge University Press, UK.

Hein J, Schierup MH, Wiuf C (2005) Gene Genealogies, Variation and Evolution. Oxford University Press, UK.

Hey J (2005) On the number of New World founders: a population genetic portrait of the peopling of the Americas. Public Library of Science Biology, 3, e193.

Hey J, Machado CA (2003) The study of structured populations new hope for a difficult and divided science. Nature Reviews Genetics, 4, 535-543.

Hey J, Nielsen R (2004) Multilocus methods for estimating population sizes, migration rates and divergence time, with applications to the divergence of Drosophila pseudoobscura and D. persimilis. Genetics, 167, 747-760.

Hofreiter M, Serre D, Rohland N et al. (2004) Lack of phylogeography in European mammals before the last glaciation. Proceedings of the National Academy of Sciences, USA, 101, 12963-12968.

Hudson RR, Coyne JA (2002) Mathematical consequences of the genealogical species concept. Evolution, 56, 1557-1565.

Hudson RR, Turelli M (2003) Stochasticity overrules the 'three-times' rule: genetic drift, genetic draft, and coalescence times for nuclear loci versus mitochondrial data. Evolution, 57, 182-190.

Johnsgard PA (2002) Grassland Grouse and Their Conservation. Smithsonian Institute Press, Washington D.C.

Johnson JA, Bellinger MR, Toepfer JE, Dunn PO (2004) Temporal changes in allele frequencies and low effective population size in greater prairie-chickens. Molecular Ecology, 13, 2617-2630.

Johnson JA, Dunn PO (2006) Low genetic variation in the heath hen prior to extinction and implications for the conservation of prairie-chicken populations. Conservation Genetics, 7, 37-48.

Johnson JA, Toepfer JE, Dunn PO (2003) Contrasting patterns of mitochondrial and microsatellite population structure in fragmented populations of greater prairie-chickens. Molecular Ecology, 12, 3335-3348.

Knowles LL (2004) The burgeoning field of statistical phylogeography. Journal of Evolutionary Biology, 17, 1-10.

Knowles LL, Maddison WP (2002) Statistical phylogeography. Molecular Ecology, 11, 2623-2635.

Lavery S, Moritz C, Fielder DR (1996) Genetic patterns suggest exponential population growth in a declining species. Molecular Biology and Evolution, 13, 1106-1113.

Leonard JA, Wayne RK, Cooper A (2000) Population genetics of ice age brown bears. Proceedings of the National Academy of Sciences, USA, 97, 1651-1654.

Manel S, Gaggiotti OE, Waples RS (2005) Assignment methods: matching biological questions with appropriate techniques. Trends in Ecology and Evolution, 20, 136-142.

Masta SE, Laurent NM, Routman EJ (2003) Population genetic structure of the toad Bufo woodhousii: an empirical assessment of the effects of haplotype extinction on nested cladistic analysis. Molecular Ecology, 12, 1541-1554.

Miller CR, Waits LP (2003) The history of effective population size and genetic diversity in the Yellowstone grizzly (Ursus arctos): implications for conservation. Proceedings of the National Academy of Sciences, USA, 100, 4334-4339.

Nielsen R (2001) Statistical tests of selective neutrality in the age of genomics. Heredity, 86, 641-647.

Nielsen R, Wakeley J (2001) Distinguishing migration from isolation: a Markov chain Monte Carlo approach. Genetics, 158, 885-896.

Omland KE, Baker JM, Peters JL (2006) Genetic signatures of intermediate divergence: population history of Old and New World Holarctic ravens (Corvus corax). Molecular Ecology, 15, 795-808.

Palkovacs EP, Oppenheimer AJ, Gladyshev E et al. (2004) Genetic evaluation of a proposed introduction: the case of the greater prairie chicken and the extinct heath hen. Molecular Ecology, 13, 1759-1769.

Pannell JR (2003) Coalescence in a metapopulation with recurrent local extinction and recolonization. Evolution, 57, 949-961.

Paulo OS, Jordan WC, Bruford MW, Nichols RA (2002) Using nested clade analysis to assess the history of colonization and the persistence of populations of an Iberian lizard. Molecular Ecology, 11, 809-820.

Pearse DE, Crandall KA (2004) Beyond $F_{\mathrm{ST}}$ : analysis of population genetic data for conservation. Conservation Genetics, 5, 585-602.

Peters JL, Gretes W, Omland KE (2005) Late Pleistocene divergence between eastern and western populations of wood ducks (Aix sponsa) inferred by the 'isolation with migration' coalescent method. Molecular Ecology, 14, 3407-3418.

Pielou EC (1991) After the Ice Age: the Return of Life to Glaciated North America. University of Chicago Press, Chicago.

(c) 2007 The Authors Journal compilation @ 2007 Blackwell Publishing Ltd 
Posada D, Crandall KA (1998) Modeltest: testing the model of DNA substitution. Bioinformatics, 14, 817-818.

Posada D, Crandall KA (2001) Intraspecific gene genealogies: trees grafting into networks. Trends in Ecology \& Evolution, 16, 37-45.

Posada D, Crandall KA, Templeton AR (2000) GEODIs: a program for the cladistic nested analysis of the geographical distribution of genetic haplotypes. Molecular Ecology, 9, 487-488.

Quinn TW (1992) The genetic legacy of Mother Goose; phylogeographic patterns of lesser snow goose Chen caerulescens caerulescens maternal lineages. Molecular Ecology, 1, 105-117.

Quinn TW, Wilson AC (1993) Sequence evolution in and around the control region in birds. Journal of Molecular Evolution, 37, 417-425.

Rogers AR, Harpending H (1992) Population growth makes waves in the distribution of pairwise genetic differences. Molecular Biology and Evolution, 9, 552-569.

Rosenberg NA (2003) The shapes of neutral gene genealogies in two species: probabilities of monophyly, paraphyly, and polyphyly in a coalescent model. Evolution, 57, 1465-1477.

Rosenberg NA, Nordborg M (2002) Genealogical trees, coalescent theory and the analysis of genetic polymorphisms. Nature Reviews Genetics, 3, 380-390.

Ross JD, Arndt AD, Smith RFC, Johnson JA, Bouzat JL (2006) Reexamination of the historic range of the greater prairie chicken using provenance data and DNA analysis of museum collections. Conservation Genetics, 7, 735-750.

Rozas J, Sánchez-DeI, Barrio JC, Messeguer X, Rozas R (2003) DNASP. DNA polymorphism analyses by the coalescent and other methods. Bioinformatics, 19, 2496-2497.

Samson FB, Knopf FL (1994) Prairie conservation in North America. Bioscience, 44, 418-421.

Samson FB, Knopf FL, Ostlie WR (2004) Great Plains ecosystems: past, present, and future. Wildlife Society Bulletin, 32, 6-15.

Schneider S, Excoffier L (1999) Estimation of past demographic parameters from the distribution of pairwise differences when the mutation rates vary among sites: application to human mitochondrial DNA. Genetics, 152, 1079-1089.

Schroeder MA, Robb LA (1993) Greater prairie-chicken. In: The Birds of North America, No. 36 (eds Poole A, Stettenheim P, Gill F). The Academy of Natural Sciences, Philadelphia; The American Ornithologists' Union, Washington D.C.

Silvy NJ, Peterson MJ, Lopez RR (2004) The cause of the decline of pinnated grouse: the Texas example. Wildlife Society Bulletin, 32, $16-21$.

Simonsen KL, Churchill GA, Aquadro CF (1995) Properties of statistical tests of neutrality for DNA polymorphism data. Genetics, 141, 413-429.

Singh RS, Uyenoyama MK, eds (2004) The Evolution of Population Biology. Cambridge University Press, UK.

Sites JW Jr, Marshall JC (2004) Operational criteria for delimiting species. Annual Review of Ecology, Evolution and Systematics, 35, 199-227.

Slatkin M, Hudson RR (1991) Pairwise comparisons of mitochondrial DNA sequences in stable and exponentially growing populations. Genetics, 129, 555-562.

Smith CI, Farrell BD (2005) Phylogeography of the longhorn cactus beetle Moneilema appressum LeConte (Coleoptera: Cerambycidae): was the differentiation of the Madrean sky islands driven by Pleistocene climate changes? Molecular Ecology, 14, 3049-3065.

Smith TB, Wayne RK, eds. (1996) Molecular Genetic Approaches in Conservation. Oxford University Press, New York.
Spaulding AW, Mock KE, Schroeder MA, Warheit KI (2006) Recency, range expansion, and unsorted lineages: implications for interpreting neutral genetic variation in the sharp-tailed grouse (Tympanuchus phasianellus). Molecular Ecology, 15, 23172332.

Tajima F (1989a) Statistical method for testing the neutral mutational hypothesis by DNA polymorphism. Genetics, 123, 585-595.

Tajima F (1989b) The effect of change in population size on DNA polymorphism. Genetics, 123, 597-601.

Tajima F (1993) Measurement of DNA polymorphism. In: Mechanisms of Molecular Evolution. Introduction to Molecular Paleopopulation Biology (eds Takahata N, Clark AG), pp. 37-59. Japan Scientific Societies Press/Sinauer Associates, Tokyo/ Sunderland, Massachusetts.

Templeton AR (1998) Nested clade analyses of phylogeographic data: testing hypotheses about gene flow and population history. Molecular Ecology, 7, 381-397.

Templeton AR (2004) Statistical phylogeography: methods of evaluating and minimizing inference errors. Molecular Ecology, 13, 789-809.

Templeton AR, Boerwinkle E, Sing CF (1987) A cladistic analysis of phenotypic associations with haplotypes inferred from restriction endonuclease mapping. I. Basic theory and an analysis of alcohol dehydrogenase activity in Drosophila. Genetics, 117, 343-351.

Templeton AR, Routman E, Phillips CA (1995) Separating population structure from population history: a cladistic analysis of the geographical distribution of mitochondrial DNA haplotypes in the tiger salamander, Ambystoma tigrinum. Genetics, 140, 767-782.

Templeton AR, Sing CF (1993) A cladistic analysis of phenotypic associations with haplotypes inferred from restriction endonuclease mapping. IV. Nested analyses with cladogram uncertainty and recombination. Genetics, 134, 659-669.

Wakeley JW (2004) Inferences about the structure and history of populations: coalescents and intraspecific phylogeography. In: The Evolution of Population Biology (eds Singh RS, Uyenoyama MK), pp. 193-215. Cambridge University Press, Cambridge, UK.

Weber DS, Stewart BS, Lehman N (2004) Genetic consequences of a severe population bottleneck in the Guadalupe fur seal (Arctocephalus townsendi). Journal of Heredity, 95, 144-153.

Westemeier RL, Brawn JD, Simpson SA et al. (1998) Tracking the long-term decline and recovery of an isolated population. Science, 282, 1695-1698.

Wiens JJ, Penkrot TA (2002) Delimiting species using DNA and morphological variation and discordant species limits in spiny lizards (Sceloporus). Systematic Biology, 51, 69-91.

The authors are interested in the ecology, evolution and conservation of natural populations. Jeff Johnson conducted this research as part of his PhD. research. He is now an Assistant Research Scientist at the University of Michigan focusing on avian conservation and systematics. Peter Dunn is an Associate Professor who studies avian mating systems and conservation genetics. Juan Bouzat is an Associate Professor primarily interested in the effects of small population size, fragmentation and geographical isolation on the genetic diversity of natural populations. 


\section{Supplementary material}

The following supplementary material is available for this article:

Table S1 Partial list of museum specimens used in study. Additional historical samples reported elsewhere (see Johnson et al. 2004; Johnson \& Dunn 2006).

Table S2 Distribution of $121 \mathrm{mtDNA}$ control region haplotypes for historical (Hist.) and contemporary populations of Attwater's prairie-chicken (Attwater's PC) and greater prairie-chicken (Greater PC). The total number of individuals sampled in each population $(N)$, total number of haplotypes, and absolute frequency of each haplotype are indicated

Fig. S1 Nested cladograms for (A) historical and (B) contemporary prairie-chicken parsimony networks.

Fig. S2 Results from NCA for the historical prairie-chicken samples. Significantly large $(L)$ or small $(S) D_{\mathrm{C}^{\prime}} D_{\mathrm{n}^{\prime}}$ and I-T values are indicated along with the inference made for clades showing significant associations. Interior clades are indicated by grey shading.
Fig. S3 Results from NCA for the contemporary prairie-chicken samples. Significantly large $(L)$ or small $(S) D_{\mathrm{c}^{\prime}} D_{\mathrm{n}^{\prime}}$ and I-T values are indicated along with the inference made for clades showing significant associations. Interior clades are indicated by grey shading.

Fig. S4 Results from NCA for combined historical and contemporary prairie-chicken samples (without contemporary Wisconsin, Illinois, and Attwater's). Significantly large $(L)$ or small $(S) D_{\mathrm{c}^{\prime}}$ $D_{n^{\prime}}$ and I-T values are indicated along with the inference made for clades showing significant associations. Interior clades are indicated by grey shading.

This material is available as part of the online article from: http://www.blackwell-synergy.com/doi/abs/10.1111/ j.1365-294X.2007.03285.x

(This link will take you to the article abstract).

Please note: Blackwell Publishing are not responsible for the content or functionality of any supplementary material supplied by the authors. Any queries (other than missing material) should be directed to the corresponding author for the article. 